\title{
Living with Lupus in Ottawa, Ontario: An Exploration of Illness Narratives
}

$$
\text { By }
$$

Melinda Spry

A thesis submitted to the Faculty of Graduate and Postdoctoral Affairs in partial fulfillment of the requirements for the degree of

Master of Arts

In

Anthropology

Carleton University

Ottawa, Ontario

(C) 2014, Melinda Spry 


\section{Acknowledgements}

At times the completion of this thesis seemed very far away and hard to obtain, but through the support and encouragement of certain individuals the project came to fruition. The research involved in this work turned out to be more of an emotional journey then I had first expected, so I would first like to thank those who shared their personal stories with me, as without you there would be no work. I would like thank the individuals at Lupus Ontario for helping for helping me find my research participants.

Furthermore, I would like to thank Dr. Jen Pylypa, my supervisor and Dr. Alexis Shotwell, my committee member, for their guidance throughout the thesis project. When I started this project I admittedly had no idea what I was doing and flitted through a few ideas before finally settling on this one. Both showed great support and patience, but especially Jen, who was very patient when I was choosing a topic. Thank you for also being understanding when this project took me a little longer to complete, then was originally expected, due to personal reasons. Without your combined theoretical and grammatical knowledge this thesis would not be what it is today, so thank you both for your time and considerations.

When I first moved to Ottawa to complete my degree, I knew only a handful of people in the Ottawa area. I additionally had moved here at a very emotional and hard point in my life, however, shortly after arriving I met the rest of my anthropology cohort. Without their friendship and support, I do not think the transition into this program at that point in my life would have gone as smoothly as it did. I will always fondly remember our dinners out and our many theoretical fun discussions. You have all had a profound impact on my life. I also could not have done this without the support of some of my coworkers from my part-time job, I held while completing this degree. Some of you I have come to consider very close friends and you have been nothing, but supportive throughout my degree. For this support I thank you.

I would also like to thank both my mother, Cindy Spry and my father, Tom Spry for always supporting me in my academic and personal life. You have always been there for me, whether I needed a person to talk to or even needed financial help. You two have been through so much and it makes me proud to say I am your daughter. Thank you for encouraging me to always be myself. I would also like to thank my friends and extended family who do not necessarily reside in the Ottawa area, but have been a constant support system to me throughout the years, without you I would not be where I am today.

Finally I would like to dedicate this work to the following two people. First is the woman who inspired this research, my mother, Cindy Spry. For all the health obstacles she has had to overcome and personal obstacles as well, she is the strongest person I know. She is more than a mother to me and I am proud to also call her a friend. From the 
time I was little she has always encouraged me to follow my dreams and that I was capable of anything if I kept at it. If it had not been for her as an inspiration, I do not think I would have endeavored this project. The second person I wish to dedicate this work to is my late brother, Mike Spry, who passed away four months before I moved to Ottawa to complete this research of a Sudden Arrhythmic Death Syndrome. He was always very supportive of me pursuing my dreams and was very happy when I got my acceptance to Carleton. His absence has been very hard on me over the past couple of years, and it has reshaped who I am as a person. Although gone, he remains an inspiration to me as he was always full of life. Thank you both for being a part of my life past and present. 


\begin{abstract}
Lupus is a chronic illness that is characterized by a series of unpredictable flare-ups and is known to affect different sufferers to varying degrees. This thesis explores the many barriers and limitations that are suffered by these individuals both in the public sphere and in some more private aspects of life, as well as beginning to question the limitations of Canada's 'universal' health care system for the treatment and support of chronic illness sufferers. First, after a brief overview of illness narratives and how they can be used to analyze different aspects of illness, the social aspects of the illness experience are explored. Secondly, I examine the more structural aspects of this experience by looking at the barriers to care and other support services which those with lupus endure. By focusing on these social and structural aspects, this thesis demonstrates that in general, lupus sufferers experience varying degrees of delegitimization of their illness experience, sometimes resulting in a delay in care or inaccessibility of necessary services.
\end{abstract}




\section{Table of Contents}

Acknowledgements

Page II-III

Abstract

Page IV

Table of Contents

Page V-VI

Chapter 1-Introduction

Page 1

What is Lupus?

Page 6

Methodology

Page 10

Chapter Outline and Overview

Page 13

Chapter 2 - Illness Narratives and How they Aid in Revealing Social and Structural Issues of Illness: A Literature Review

Page 16

Stigma

Page 20

Disability, Queer Theory and the 'Sick Role'

Page 26

Access to Care and the Dangers of Gendering an IIIness

Page 31

Conclusion

Page 34

Chapter 3 - From Limitations to Stigma to Thwarted Dreams: Lupus and Social Aspects of Life

Page 35

General Limitations on Life

Page 35

Informant and Public Understandings of Lupus

Page 40

Support Systems and Dealing with a Lack of Support

Page 42

Body Image Issues

Page 45

The Gendered Experience of Lupus

Page 47

Fears about the Future and Thwarted Dreams

Page 49

Stigma

Page 51

Depression, Psychological Impact and Emotional Coping

Page 54

Conclusion

Page 55

Chapter 4-Barriers in Life: Lupus and Structural Aspects of Life

Page 59

Case Study: Mary's Story

Page 60

Accessibility to Care

Page 61

Patients' Feelings about Practitioner Care

Page 65

Chronic IIIness in the Workforce

Page 70

Episodic Disability

Page 77

Conclusion

Page 79

Chapter 5-Conclusion

Page 84 
Works Cited

Page 89 


\section{Chapter 1-Introduction}

Medical care in Canada is often portrayed as being available to all, yet it is failing to meet the needs of those living with chronic conditions such as lupus. Those with chronic illnesses often face barriers to care, that are further complicated by other social issues that they deal with on a daily basis. Arguably, lupus is an under-researched chronic illness that has become more prominent in the last decade, due to a larger aging population living with chronic illnesses. Lupus is characterized by a series of flare-ups, when symptoms become exacerbated, and periods of remission, when symptoms subside (Murphy, Spence, McIntosh and Gorber 2006: 25). Lupus is classified as an autoimmune disease, in which an individual's immune system becomes heightened to the point of recognizing healthy tissue as foreign, essentially causing the body to attack itself. This manifests in varying ways; symptoms can include a malar rash, chronic fatigue, chronic pain, joint inflammation and complications with major organ systems. Most of the research that is being done on lupus focuses on clinical aspects of the illness, but shies away from exploring how having this illness affects those who are afflicted in their daily lives. The aims of this research project were to give voice to those who are afflicted and to explore some of the daily struggles that the average person with lupus deals with. This was achieved through a series of semi-structured interviews with 14 lupus sufferers in Ontario.

I started this project with four main questions in mind:

1. How do people with lupus perceive their illness and their limitations (if any)?

2. How do they feel lupus is perceived by others (doctors, laypersons, family)? 
3. Does a formal diagnosis of lupus shift individuals' perceptions of themselves and the perceptions others hold of them?

4. How has this formal diagnosis impacted them, and how does it impact their conceptions of their future?

Through the guidance of these four root questions I was able to ascertain concerns regarding not only social impacts of having lupus, but also structural impacts. Some of social aspects the research highlighted included: a high and varied experience with stigma both from family and the public, issues associated with body image due to treatment and disease effects, and issues dealing with depression. These questions also revealed structural issues, such as whether accessible and adequate medical care has been available for these individuals, issues associated with employment and issues in the ability to claim support resources. In this thesis, I will take up these issues to argue that health care in Canada is not adequately meeting a growing need for additional resources and support services, especially in a society that values productivity.

Lupus is considered an 'invisible' chronic illness, which means that people with this illness may be deemed 'visibly' healthy by the general population and as a result could face discrimination and misunderstanding when they disclose their status as chronically ill. As a result of this, patients find themselves searching for ways to convey what it is like to live with lupus to those to whom they choose to disclose their illness. One anecdote, given to me by Breanna ${ }^{1}$ and mentioned by others throughout the

\footnotetext{
${ }^{1}$ Names have been changed to pseudonyms to protect the identity of participants.
} 
interview process, was 'The Spoon Theory', first described by Christine Miserandino (2003). In this anecdote Miserandino (2003) states that, The difference in being sick and being healthy is having to make choices or to consciously think about things when the rest of the world doesn't have to. The healthy have the luxury of a life without choices, a gift most people take for granted.

In this anecdote, Miserandino (2003) illustrates how these choices affect her day by giving her friend a certain number of spoons to start the day and taking them away as she talks about completing everyday tasks (Miserandino 2003). She also states that sometimes you start out with more or less spoons than on other days, so it is hard to know what you will be able to complete that day (Miserandino 2003). Although I will discuss the more scientific definition of lupus in another section, I believe it is important to start by understanding how being ill in this way can affect the daily lives of the individuals afflicted. Even though individuals may not be 'visibly' ill, they are unable to complete everyday tasks in the same manner as other people and may have to make choices about what gets done today and what gets left undone. 'The Spoon Theory' is regarded by many lupus sufferers as a way of explaining to friends and family, who may have a hard time understanding, what it means to live with lupus and was given to me to read by one of my participants and mentioned by two others.

Many people have asked me why I chose to study lupus and the answer for that is simple: my mother has lupus, although she was not formally diagnosed with lupus until I had already started this study. Seeing my mother struggle for over 15 years for a 
diagnosis and fight her way through the medical system made me wonder how widespread her experiences were, if they were unique to her, or if other people suffered in similar ways. She faced barriers to accessing care due to a doctor who did not believe her complaints and at times even told her that her symptoms were psychosomatic or 'all in her head'. She suffers from several secondary conditions associated with lupus such as Sjögren's syndrome and connective-tissue disease. In addition, she suffers from primary rheumatoid arthritis, which is potentially made worse by her lupus. Due to complications with her undiagnosed lupus, she has been in and out of the medical system and treated with varying degrees of dismissal along the way. She eventually gained a diagnosis after pleading with her surgeon in a follow-up appointment after one of the procedures she endured, for a referral to a rheumatologist. Through an initial literature review and an overview of what was available on the Internet, it seemed as though some of her struggles did resonate with others, but others did not. Although this started out as the main motivation for my research, my analysis will focus mainly on the participants' testimony, with my mother's experiences providing an additional anecdote or two to expand upon the discussion.

One parallel that I found between my mother's experiences and those of others, was the lack of rheumatologists (designated specialists that treat patients with lupus and other autoimmune conditions), resulting in many referrals getting turned away (Delaurier et al 2012:2). When patients do get an accepted referral they can still wait between three to six months for their first appointment (Fitzgerald et al. 2011:231). This results in a critical delay in treatment, especially for those with major organ involvement. However, 
it should be noted that referrals are taken on, on a needs basis and not a first-come-firstserve basis, which means those who need critical care are able to access it first. This illustrates that there is a need for more rheumatologists in the Ottawa area and Canada as a whole, as well as a need for more research to be completed. The resulting barrier to care this creates will be discussed in Chapter 4.

Although this concept with be explored in further detail later, I will refer to lupus as an episodic disability, in that "episodic disabilities are conditions characterized by unpredictable, fluctuating periods of illness and wellness that wreak havoc with a person's health, income stability and quality of life" (Vick 2012:42). The impact of episodic disability points to the importance of discussion around public policy, as well as the effects of societal pressures. Moreover, it encourages a discussion of what it means to live with a chronic condition that may have no effect one day, but at the same time not enable you to get up the next. Through a discussion of episodic disability, I hope to illustrate that both the dichotomies of disabled/abled and sick/healthy are not binary, but rather that they lie on a spectrum that can fluctuate. Currently, in our society we seem to view these concepts as binary opposites, but this is not necessarily true with the emergence of more and more chronic illnesses as we live longer (Vick 2012:43). It is therefore one of my intentions to argue for a more fluid definition of sick/healthy and disabled/abled, as Vick has done with her work involving patients who have multiple sclerosis.

Another intention of this study is to provide a glimpse into some important aspects of living with an 'invisible' chronic illness that may not always be talked about in 
length. One such topic that I will explore is the issues of body image. Although lupus is considered 'invisible' that is not always the case. Discoid lupus (lupus that affects the skin) can be quite visible and additionally treatments such as prednisone can affect the outward appearance of the individual, resulting in concerns over body image. Another topic that I will explore is the issue of disclosure, or rather how one goes about deciding whom they should and should not tell and the consequences these choices can have. Additionally, I will explore in what ways the participants self-identified with lupus and in which ways they either rejected this identity or felt indifferent to it. Every individual's experience with lupus varies, so it is therefore my intention to also emphasize that there is no single story that accounts for all, however, there are similarities among different people's illness narratives.

\section{What is Lupus?}

Although I have mentioned 'The Spoon Theory' as one way in which some participants describe their illness, I will expand upon this by briefly going over how most of the informants described their illness followed by how the biomedical profession views lupus. For most informants, they described lupus as being an autoimmune disease in which their immune system became heightened and started to attack them, instead of only attacking foreign matter. Due to this process, most informants described feelings of extreme fatigue and general discomfort. Symptoms across informants varied in type, severity and duration, which will be discussed in more detail in Chapter 3 . 
Lupus is a rheumatic autoimmune disease that affects about 1 in 1000 Canadians, and is 9 times more prevalent among women and ethnic minorities than among the population as a whole (Lupus Canada 2014). It is known as 'the disease of 1000 faces' as it can manifest quite differently from individual to individual (Murphy et al. 2006: 26). There are two types of lupus: discoid lupus which affects only the skin of the individual, and systemic lupus erythematosus (SLE) that affects an individual's major organ systems (Voss and Casperson 1988:2). When fighting off an infection it is normal for a person's body to produce antibodies which will instruct white blood cells to attack the foreign material in the body. Someone afflicted with lupus has a heightened immune system, which sometimes results in the production of anti-DNA antibodies or rather antibodies that recognize one's own bodily tissue as foreign (Voss and Casperson 1988:2). In most cases, but not all, lupus can be diagnosed and detected through a blood test to assess the presence of anti-DNA antibodies (Voss and Casperson 1988:2). However, if these antiDNA antibodies are not present, it does not mean an individual does not have lupus, because the disease can manifest in differing ways (Voss and Casperson 1988:2).

Although there are many symptoms associated with lupus, some of the more common symptoms include the presence of a "malar ('butterfly') rash all over the cheeks of the face; discoid skin rash (patchy redness on the skin); photosensitivity; oral ulcers; arthritis in two or more joints of the extremities; serositis; renal disorder; neurologic disorder; blood count abnormalities; immunologic disorder; and antinuclear antibodies" (Murphy et al. 2006:27). Commonly, individuals must present with four of the above symptoms to receive a concrete diagnosis (Murphy et al. 2006:27). Since lupus manifests 
differently in each individual, it can be difficult to diagnose, resulting in a delay of care. Lupus can also cause secondary conditions such as vasculitis (a chronic condition that involves constricting of the blood vessels), Sjögren's syndrome (a chronic condition that involves problems with the salivary glands), Reynolds phenomenon (a chronic condition that affects the circulation of blood to certain parts of the body, especially in the hands) and rheumatoid arthritis (a chronic condition that involved the swelling and deformity of joints) (Murphy et al. 2006:27). Most participants in this study noted feeling general fatigue and unexplained pain throughout their bodies as the first symptoms that they encountered.

The exact causation of lupus is not entirely known, but current theories point to genetic predisposition, antibiotics and environmental stressors as possible factors (Murphy et al. 2006:27). In general there seems to be a lack of research into finding out what causes lupus, which could also hinder finding new treatments for the disease. Within my own research most informants attributed their lupus to heredity but one, Meredith, also thought it was brought on through medications she was taking at a previous time in her life. No matter what the general beliefs are on the causation of lupus, it is evident that more research needs to be done in order to find a cause.

Currently, there are a few different treatments available to suppress the symptoms of lupus, although there is no cure. The current leading prescribed treatment is plaquenil, which is also an anti-malarial drug (Hanna, Holdeman, Tang and Schiffman 2008:90). One of the biggest risks associated with this drug is the risk of ocular impairment (Hanna et al. 2008:90), and although none of my participants mentioned 
enduring this side effect, some noted that they were fearful this would happen. Other treatments currently being used to treat patients in Ottawa include corticosteroids (prednisone), immunosuppressive drugs and biological agents (McKay and Smith 2014). Past treatments were somewhat experimental and sometimes included the use of chemotherapy, which was implemented in the case of one of my participants, lan, who has been in a remissive state for over twenty years. Experimental treatments such as this have fallen out of use due to improved medical knowledge and more guidelines restricting the use of radical treatment methods. However, through attending a lecture series presentation on March 12, 2014 at the Riverside Campus Hospital in Ottawa, I learned that many of the treatments that rheumatologists prescribe for lupus are not directly approved for lupus and therefore treatment can vary from patient to patient (McKay and Smith 2014). Although this is not the normative treatment, they still use experimental treatment from time to time.

This is evident with Mary, a participant who has discoid lupus, and the regimen she has to endure to get her 'experimental' treatment month to month. In our interview she expressed in detail how she and her doctor must endure a monthly survey and pregnancy test just to receive treatment, and sometimes when the doctor reneges on his part of the survey Mary's treatment is delayed, which could result in a relapse of her condition. The last drug that was officially approved for the treatment of lupus in Canada was an immunosuppressant called belimumab in 2011; before this it had been about 10 years since the last lupus specific treatment was approved (Sanz, Yasothan and Kirkpatrick 2011:335). Belimunab was discovered and developed in the U.S. and has since 
been approved for the treatment of lupus in several countries (Sanz et al. 2011:336). It is noteworthy that the USA just approved a large grant for the study of new treatments for five major diseases, including lupus. Therefore, there may be new treatments available in the near future, but it would be hard to estimate when they would gain approval for use

in Canada. Most participants had no knowledge of this recent development at the time of interview, however, it was Breanna who brought this to my attention.

Although not as common or widespread, a number of participants noted the use of complementary therapies that they sometimes employ. These included the use of colour therapy, acupuncture, dietary changes, Reiki and the use of a naturopath. The most commonly mentioned of these alternative therapies was naturopathy. Although those that did use these methods note that they believed that they help significantly, these treatments did not replace the Western biomedical treatments that they were also taking and would only be used as a complementary tool alongside their other treatments. A few participants also mentioned the use of a therapist, which will be discussed in a later section with regard to depression.

\section{Methodology}

I chose to conduct semi-structured interviews, to allow for the participants to focus on what they felt was pertinent to their own experiences with lupus. Due to this methodology some interviews were more structured, if the participant needed to be more prompted to respond, and others were less structured if the answers were coming out in the story that they wished to convey. Interviews varied in length from 25-70 
minutes. These interviews took place in differing areas around the city of Ottawa, in mutually agreed upon meeting areas, usually a coffee shop. Interviews were recorded with permission for later transcription. Only one out of 14 declined to be recorded for personal reasons.

Participants for this study were recruited through an email mailing list maintained and owned by Lupus Ontario. A member of Lupus Ontario forwarded my recruitment email to the list and then possible participants contacted me if they required more information or they wanted to set up an interview time. Ages of the individuals at the time of interviewing ranged from 25-67 years and included twelve female and two male participants. Thirteen of the fourteen interviews were conducted in-person at prearranged destinations, while the final interview was conducted by phone. Twelve of the participants had been diagnosed with systemic lupus erythematosus, one had been diagnosed with both discoid and systemic lupus erythematosus and the last individual had been diagnosed with 'probable' systemic lupus erythematosus. Although lupus is known to disproportionately affect ethnic minorities, only 4 out of 14 participants were of non-European decent in this study. The reason my sample may disproportionately represent the minority of people with lupus may be due to the composition of the support group that was contacted. Most respondents also could be described as middle class or having a steady income.

Lupus Ontario is a not-for-profit organization that is dedicated to raising funds and awareness about lupus in Canada and was first established in 1978 (Lupus Ontario 2009). Their mission statement states that "Lupus Ontario is a team of caring enthusiastic 
volunteers and staff who are passionately committed to helping those with lupus live longer and better by raising funds that deliver vital support, education, awareness and research" (Lupus Ontario 2009). The Ottawa chapter of Lupus Ontario offers support groups in various areas of Ottawa. Additionally, in conjunction with the rheumatology clinic they provide quarterly family education nights that are open to the public which always start with a presentation that explains what effects autoimmune diseases have on the body and ends with a special presentation of various topics associated with these conditions. As a means of ascertaining what information was being disseminated to the public, I attended two of these quarterly lectures. They also coordinate a yearly walk to raise funds and awareness of lupus. This year all the funds raised are staying within Ontario to provide more educational opportunities to both professionals and the general public.

For this study, I used grounded theory as a form of analysis. Grounded theory allowed me to focus on the individual stories, rather than drawing grand conclusions from a larger population. It also allows the research to speak for itself, in that conclusions are drawn from the interviews and more importantly from what the participants wanted to say. According to Bernard (2006: 492), grounded theory "is a set of techniques for: (1) identifying categories and concepts that emerge from text; and (2) linking the concepts to substantive and formal theories." This approach allows the researcher to pull themes out of a smaller set of interviews and find similarities among them. Once themes have emerged, they then may be used to create theoretical models of analysis for the rest of the research. The use of grounded theory as a qualitative method of analysis used in the 
study of chronic illness has been extensively argued for by Kathy Charmaz (2010:10). She states that grounded theory allows the researcher to focus on the individual, rather than the collective in analysis, providing an opportunity for a diversity of perspectives to be heard (Charmaz 2010: 10). Taking a grounded theory approach to illness narratives is important as it removes the necessity of shared experience among people and allows the researcher to rely on the experience of their participants. To employ this method, initially, quotes were pulled out as exemplars from these transcriptions and narratives were compiled. From forming these narratives, I began to see patterns which led to the choice in topics for chapter two and three. Experiences that seemed individualized were also taken into account, as the variety of ways lupus physically affects the individual varies from person to person, therefore no two stories would be expected to be the same. Grounded theory allowed me to explore some of these individual experiences that are sometimes lost when a study is more focused on generalizing about the overall population.

\section{Chapter Outline and Overview}

In chapter two, I will explore previous literature written about lupus and other chronic conditions. This will include a more in-depth discussion of episodic disability and how both queer theory and disability studies add to the discussion of lupus. I will also be exploring some of Ervin Goffman's theories and how they could apply including Goffman's (1963:73-91) theory of 'passing' or rather the act of "keeping from public view a spoiled identity that was otherwise invisible" (Frank 1997: 32, Goffman: 1963:73-91), 
which an individual may have to do at work or in other social situations. This chapter will also explore previous work on 'invisible' chronic conditions and some of the theories and conclusions that have emerged, such as regarding access to care. Additionally, in this chapter, I will discuss stigma and its impact on social identity and the internalization of a spoiled identity (Goffman 1963:1-32). I will also begin discussing the sick role (Parsons 1951) and how those without clearly defined illness labels, and especially those with chronic illnesses, are often denied the benefits associated with these labels.

Expanding on some of the issues brought forth in the broader literature review, chapter three will explore the ways in which having lupus affects individuals on a personal and social level. In this chapter I will deal with issues involving stigma, body image issues, fears for the future and the uncertainty of dealing with lupus, as well as issues associated with having a chronic illness and dealing with depression. The discussion for this section will expand upon these issues and explore the reasoning behind some of the choices people make and how society influences and informs these choices. Both Norma Ware's (1992) and M. Cameron Hay's (2010) previous work on chronic illness and claiming legitimacy will be used as references for analysis.

Chapter 4 will focus on structural issues associated with lupus, or sufferers' experiences. First, barriers to accessing the medical system will be explored, including a discussion of the insufficiencies of service. Next I will discuss how informants feel they have been treated within the medical system and again look at inadequacies. I will then explore involvements with the work force and how having lupus affects the afflicted in this environment, including a discussion of what work places could be doing to lessen this 
impact. Finally, I offer a discussion of episodic disability to show the difficulty that some have endured while trying to gain access to valuable resources and services that require certain definitions of illness to be fulfilled and requirements to be met. These definitions and criteria may not necessarily coincide with the individual experience of those who require their services, so again I use this as a point to discuss how services are inadequate for those who require them.

In the concluding chapter I will bring all these issues together and discuss how the Canadian medical system is falling short of providing adequate assistance to these individuals. Additionally, I will present an overview of what it is like to be living with lupus and not necessarily have a voice. Furthermore, I will reiterate the importance for gaining a legitimate label and its potential to provide access to more support and services. It is my intention with this thesis to highlight the ways in which the Canadian medical system is not adequately addressing the needs of people living with lupus, give voice to a population that is generally silent, and provide a glimpse into what it means to be living with an 'invisible' chronic illness. 


\section{Chapter 2 - Illness Narratives and How they Aid in Revealing Social and Structural Issues of Illness: A Literature Review}

Illness narratives have generally focused on elucidating the individual experience of illness. The illness narrative tells the singular story of an individual, however, it is impossible to separate individuals from the culture and the society in which they reside. It is my intention, then, with this chapter, to begin to illustrate that illness narratives, or rather the individual stories that are told, begin to piece together a collective voice, one that is entrenched both with similarities and differences of individual experience. To illustrate this I will first outline the significance of illness narratives and how they have been used in more detail, then bring out themes that have manifested themselves in individual stories of chronic conditions, but have broader implications. These themes include stigma, defining disability, gendered experiences, and the difficulties of the sick role. These themes will be further explored in the coming chapters, during my own analysis of informants' lupus illness narratives.

The content of an illness narrative is affected by many factors including the individual's culture, social structure, and even the intended audience. According to Kleinman (1988:9), "the interpretation of illness meanings can also contribute to the provision of more effective care." It was Kleinman's intent that by allowing those afflicted by illness to tell their stories, in their own words, medical professionals might gain a better understanding of how the individual views the illness and a better understanding of what the patient personally requires for optimal care. This is an important argument as currently, "the biomedical system replaces this allegedly 'soft,' therefore devalued, psychosocial concern with meanings with the scientifically 'hard,' therefore overvalued, 
technical quest for the control of symptoms" (Kleinman 1988:9). This is evident when examining our current medical system structure, which includes patient quotas and timed appointments. In the average fifteen minute appointment the practitioner may only be able to assess a patient's immediate symptoms, and consequently may miss the social implications. It is through the narrative of the patient that we are able to understand the illness as, "acting like a sponge, illness soaks up personal and social significance from the world of the sick person" (Kleinman 1988:31).

According to Hanoko Okada's work with illness narratives, they hold three key purposes:

...first, they enable the overcoming of either/or dualisms such as mind/body, biological/social, and impairment/disability ... second, illness narratives bring together bodily, emotional, and sociocultural experience and make meaning from them ... [and] third, illness narratives can provide a voice for sufferers - those who, although they are in one sense the center of medical attention, are typically rendered silent by the biomedical community. (Okada 2011: 145-146) Similar to Kleinman, Okada argues that illness narratives often convey the underrated personal, social and cultural aspects of illness. Furthermore, Kleinman states that, the fidelity of our bodies is so basic that we never think of it - it is the certain grounds of our daily experience. Chronic illness is a betrayal of that fundamental trust. We feel under siege: untrusting, resentful of uncertainty, lost. Life becomes a working out of sentiments that follow closely from this corporeal betrayal: confusion, shock, anger, jealousy, despair. (Kleinman 1988:45) 
In particular, Kleinman argues that the narrative is imperative to understanding chronic illness and how it affects people. By giving voice to these individuals, we aid in the comprehensive understanding of how they are dealing with the chronicity of their conditions within daily life.

Although I relied on in-person interviews to collect the illness narratives of my participants, the scope of who gets a voice is changing with the abundance of Internet blogs and forums, which allow people's illness narratives to be widely disseminated. Andy Miah and Emma Rich (2008), examine how the Internet has changed the way health information is disseminated. It is no longer just physicians who are the producers of knowledge, but rather patients are having a larger impact on the dissemination of health knowledge through the use of the Internet (Miah and Rich 2008: 59). Moreover, the use of Internet forums as a space to discuss symptoms of ill health and their probable causes is on the rise (Miah and Rich 2008: 59). The Internet as a forum for those dealing with chronic conditions has proven to provide an anonymous platform free from most ridicule and has provided those with no means of accessing a face-to-face support group the means of creating an online community (Miah and Rich 2008: 61). Although this Internet phenomenon and the number of health forums that have been created is enormous, it is important to note that the use of these sites is limiting in the fact that one must have the ability to access the Internet to use them (Miah and Rich 2008: 61). Although my research does not deal with Internet forums, I feel it is imperative to note their usefulness in disseminating voices of those who may otherwise not have the opportunity to share their stories and experiences. The use of the Internet in the dissemination of 
illness narratives is not only helpful in providing a community in which people can relay experience back and forth; it has become a space where analysis of sometimes stifled voices can be drawn for the purposes of understanding the embodied experience of illness.

In an article exploring the illness narratives of patients living with lupus through the use of Internet blogs in the USA, it was found that most narratives took a similar pattern, that of transformation (Miles 2009: 6-7). An example of this transformation narrative, taken from a blog, reads as follows:

...when my arms are too weak and painful to brush my hair or when one leg refuses to support my weight, the thought of being crippled still settles like a rock in my stomach ... Yet, I adamantly refuse to entertain 'what if's.' As with anything in life acceptance and a sense or purpose are the keys to a peaceful, fulfilling life. ... Acceptance and a peaceful co-existence with your disease awaits you if you will move toward it." (Miles 2009: 7)

Although some may view their illness experience in this way, it is not always the case. Miles (2009) may have found a pattern of transformation narratives, yet not all people suffering from an illness view their illnesses in positive terms, as personally transformative. Miles' (2009) work with blogs is important to adding to a knowledge base of experience, but should be expanded and contrasted with narratives of those who do not necessarily fit this pattern and/or do not necessarily seek the Internet as a medium to share their illness experience. While the means of collecting illness narratives have changed over the years with the advancement of technology, they still carry with them 
the same main functions. The use of illness narratives in research helps disseminate knowledge that may not be otherwise known. As Kleinman (1988) has argued, these narratives should be analyzed to better understand the patient experience, so that treatments services can better provide for patients.

\section{Stigma}

One important aspect of the illness narratives of those with chronic illnesses, is often a discussion of stigma. According to Erving Goffman, stigma (1963:3) "refer[s] to an attribute that is deeply discrediting", or rather an attribute that can change one's social identity from the accepted norm to undesirable. Miah and Rich (2008:62) note that the diagnosis of a chronic illness can cause a 'biographical disruption,' stating that creating a narrative provides a way of coping with the disruption and a way to "maintain some sense of worth in the face of intrusive symptoms". Thus, debatably at diagnosis there is an initial 'biographical disruption', but this disruption is ongoing and potentially can constantly reshape the person's biography. The stigma experienced by individuals with lupus, also functions as a 'biographical disruption', as it reshapes how they interact with others and how they communicate with others about their illness. Stigma, as will be addressed specifically with regard to lupus in a later section, plays a central role in the lives of those living with chronic illness. Stigma can lead to a sense of isolation, body image issues, lower feelings of self-worth, depression and can potentially lead to a lower level of care access. 
Several studies have described different types of stigma and the effects associated with them. One such study by Earnshaw and Quinn (2011) differentiated between three types of stigma and noted that the effect of stigma was dependent on the degree and type of stigma the subject was experiencing. The first type of stigma they define is 'internalized stigma', which refers to when a person applies negative attributes to themselves that are commonly associated with their condition (Earnshaw and Quinn 2011:158). This type of stigma often leads to lower feelings of self-worth and depression (Earnshaw and Quinn 2011:158). The second type of stigma they outline is 'experienced or enacted stigma', put simply, this is the stigma felt from discrimination by others around them (Earnshaw and Quinn 2011:158). The final type of stigma they outline is 'anticipated stigma', which refers to the stigma that a person anticipates receiving due to past experiences in similar situations (Earnshaw and Quinn 2011:158).

Through their studies Earnshaw and Quinn found that a combination of internalized stigma and experienced stigma led to an increase in anticipated stigma, which in turn led to a decrease in access to care, as the patients feared being stigmatized by the healthcare providers (Earnshaw and Quinn 2011:163). To combat this, they suggest that patients should be encouraged to seek healthcare regardless of any type of stigmatization (Earnshaw and Quinn 2011: 165). This suggestion, however, fails to address why patients may feel stigmatized by healthcare providers, a sentiment they may feel strongly. For example, in Julie Devaney's book about her illness experiences, she states that, after telling the medical students what pain is really like for colitis patients, 
"I'm embarrassed that I have exposed myself to what feels like their ridicule and shaming" (Devaney 2012:203).

Furthermore, Devaney (2012:30) states that, "under-resourced health care systems create situations where everyone is funnelled through the same place to receive care. Patients are put into competition with one another in moments of critical health crisis. Health care professionals are placed in entirely untenable situations where they must choose who needs them the most." She made this statement after being in a lecture that referred to chronically ill patients who use emergency services as 'bed blockers'. Sometimes due to unforeseen circumstances people with chronic illnesses find themselves in situations that require immediate emergency care and are unable to see their specialist doctors. In these instances they are viewed by some as misappropriating services, but as Devaney (2012:30) points out they have no choice in their use. Due to her own experiences as a patient, Devaney travels around giving talks for medical students, the public and other professional spheres in an aim to try and refocus people's thoughts on what it means to be a patient. In these talks she usually starts out by wearing a hospital gown and if the situation permits, uses a hospital bed (Devaney 2012). Through these talks she hopes to provide insight into what it means to be a patient and to show that the patient is not just their illness that needs to be fixed, but a person (Devaney 2012:298). Many of those who have chronic illnesses face judgement within and outside of the medical care system. Experiences such as Julie Devaney's and how she actively tries to combat the ways that those in the medical sphere view patients illustrate alternative approaches to lessoning the stigma that is enacted upon the chronically ill. It 
is not enough just to encourage patients to seek care regardless of how they are treated, but rather it is important to try and make it so that people feel comfortable actively seeking this care.

Those who anticipate, experience or internalize stigma are likely to take measures to avoid stigmatization. As will be discussed in a subsequent chapter, this can be due to not wanting to be discredited or wanting to be seen as 'normal'. This is generally achieved through a phenomenon known as 'passing', which can be defined as "deliberate concealment ... The goal of passing is to become part of the 'normal' group" (Joachim and Acorn 2000:245). In Joachim and Acorn's (2000:245) study on stigma and chronic illness, they state that people who do not have visible indicators of illness must choose how and to whom they should disclose their illness. Furthermore, they state that disclosure of illness can lead to either support and sympathy or stigma and isolation, which in turn can lead to stress (Joachim and Acorn 2000:246). They discuss how people go about deciding when to disclose and when not to, which will be one aspect that I address within my own analysis.

Stigma and how it affects those living with chronic illnesses, especially those illnesses that are at times 'invisible' and at other times 'visible,' has not been discussed until recently. A recent study conducted by Sehlo and Bahlas (2013), sought to link 'anticipated' stigma and the rate of depression among female patients living with systemic lupus erythematosus in Saudi Arabia. Among their sample of eighty female patients it was found that $18.75 \%$ suffered from some degree of depression (Sehlo and Bahlas 2013:249). This is significant as their study showed that depression was still 
prevalent among those without central nervous system involvement and was linked to lowered feelings of self-worth due to their diagnosis (Sehlo and Bahlas 2013:250). Through my own research I found that a number of participants sought out therapy and/or detailed periods of depression for various reasons, which will be discussed in a later section in more detail.

One stressor leading to stigma and depression that I had not anticipated, but that emerged from my interviews, was issues with body image. As lupus is generally thought of as an 'invisible' chronic illness, aspects that can make it visible directly or indirectly can have a strong negative impact on those afflicted. Although this will become more apparent in my analysis, I would like here to note a couple of a studies conducted by Hale et al. (2006:532) and Jolly et al. (2012: 157) that address the more outwardly visible signs of illness that can manifest themselves in patients with lupus either as a direct result of the illness or as a result of treatment. Some observable physical symptoms of SLE can be joint swelling, alopecia, spontaneous rashes, permanent scarring and loss of pigmentation in the skin (Hale et al. 2006:532). Furthermore, the use of steroids, like prednisone, can often lead to extreme weight fluctuations (Hale et al. 2006:532). The study talks about increased rates of isolation and methods of concealment the patients would use in order to hide the more visible aspects of SLE (Hale et al. 2006:538). Similarly, Jolly et al.'s more recent study of lupus correlates a negative body image (due to the visible aspects of SLE) with depression, and the suggestions she makes to combat this are as follows, "(a) use of sunscreens, (b) early referrals, aggressive screening, and treatment of active disease using evidence-based pharmaceutical strategies to limit 
disease activity, limit organ involvement and prevent damage, (c) cosmetic camouflage training, (d) early diagnosis, referral and treatment of depression, and (e) self-esteem and coping exercises" (Jolly et al. 2012:163). Jolly et al (2012:162) note that without these types of interventions negative body image accompanying lupus can potentially lead to an increase in risky health behaviours and an increase in poor health outcomes.

Considering SLE is thought to be an 'invisible' chronic illness, there has not much information on body image issues or other related outward signs that could create stigma until the last few years. Although these tend to be a good start in assessing a largely underrepresented aspect of living with lupus, they still fail to fully assess what this means for the individual afflicted. It is becoming increasingly necessary to assess what they fear about their futures, their families and about their lives in general. Discussions of stigma, as noted in most studies, have dealt specifically with physical appearance, but they seem to be missing a major component of lupus. Most lupus sufferers deal with issues involving chronic fatigue and chronic pain that may not be visible, but can significantly affect their ability to complete daily tasks at certain times. Through a lack of public knowledge or acknowledgement these people can feel that others view them as lazy or incompetent as well. So although looking at stigma in relation to body image is very important, especially with the use of steroids like prednisone, it should not be limited to this as body imagerelated stigma does not encompass the whole picture. 


\section{Disability, Queer Theory and the 'Sick Role'}

Another important aspect of illness narratives is how differing identities and their social definition affect a person's claim to care. All disability support programs in Canada define disability in their own manner and there are no agreed upon criteria. This has led some organizations and agencies that have support systems to frame disability in a very specific manner that tends to be a binary system: one is either 'disabled,' or not (Vick 2012:42-43). For those living with chronic illnesses that have periodical flare-ups like lupus, disability can exist on a sliding scale (Vick 2012:42-43). This means that from day to day the individual may not be able to complete tasks that they could the day before their flare-up, and which they may be able to complete when their illness is asymptomatic again. Some scholars have taken to calling this 'episodic disability', which refers to "conditions characterized by unpredictable, fluctuating periods of illness and wellness that wreak havoc with a person's health, income stability and quality of life" (Vick 2012:42). Vick (2012) has completed several studies that begin to probe the Canadian disability policies and the effects that they are currently having on individuals who have illnesses that can be categorized as episodic disabilities. Some of these conditions include "multiple-sclerosis, chronic fatigue syndrome, fibromyalgia, inflammatory bowel disease, multiple chemical sensitivities, lupus, epilepsy, asthma, arthritis, diabetes, cystic fibrosis, heart disease, chronic pain, musculoskeletal conditions, cancer, HIV/AIDS, and mental health conditions" (Vick 2013:177).

Previous scholars have argued that episodic disability should be placed as a sort of in-between condition. Vick (2012:178) argues that 
positioning episodic disabilities as an in-between embodiment does not reify flux or the complete dissolution of any one identity but highlights the constitutive permeability of moving back and forth between embodied states and identities. From this vantage point, individuals threaten the logic of classificatory systems by straddling boundaries as neither properly well nor properly sick, which puts them between the statuses of sick and well, able and disabled.

Yet this in-between status can lead these individuals to being in a sort of liminal state, or rather, not fitting into the socially accepted categories set out by the society in which they reside.

Similarly, Talcott Parsons' (1951) concept of the 'sick role' leads us to a discussion of how people with chronic illnesses, such as lupus, find themselves in a liminal state, where they are unable to fulfill all the requirements of occupying the 'sick role'. Parsons (1951: 193) defines his conception of the 'sick role' as entailing a dependent state in which the individual has a legitimate claim to be 'taken care of.' However, Parsons states that, "the claim to be taken care of is made contingent on admission that it would be a good thing to get well as expeditiously as possible" (Parsons 1951: 197). Parsons (1951:198) argues that a person who does not seek to become well again or rather a 'productive citizen' of society is therefore seen as deviant. It is "an institutionalized role ... Instead of an almost absolute illegitimacy, the sick role involves a relative legitimacy, that is so long as there is an implied 'agreement' to 'pay the price' in accepting certain disabilities and the obligation to get well”' (Parsons 1951:211). Although Parsons' conception of the 'sick role' accurately labeled those suffering from acute illnesses in the 
mid-twentieth century, it places those suffering from chronic illnesses in the twenty-first century into an illegitimate state as they are not able to fulfill the obligation of becoming well again (Spry 2013, Cazdyn 2012:18). Arguably, a conception of the 'sick role' is useful, however its premise and terms do not fit those who suffer from chronic illness and therefore it may need to be re-evaluated to fully address the rise of chronicity.

Furthermore, Ann Miles' (2013:60-61) argues in her book entitled Living with Lupus: Women and Chronic Illness in Ecuador, that when the chronically ill person fails to fulfill the social obligation to become well again or rather a productive citizen of society, that individual can face further stigmatization. This, in turn, can lead to increased rates of depression and isolation. She further argues that, like other chronic conditions that have been described as 'invisible', such as chronic fatigue syndrome (CFS), a lack of understanding and knowledge by both professionals and lay people can lead the sufferer to feel stigmatized (Miles 2013:63). Miles states that, "chronic pain sufferers are often viewed by doctors, friends, and family as possible hypochondriacs who might be making 'a mountain out of a molehill'” (Miles 2013:62-63). This is due in part to a lack of understanding that people could be living in periodic or constant debilitating pain for years with no outward signs (Miles 2013:63). She argues that this misunderstanding and inability to be categorized as either sick or well leads to stigmatization as it "opens up questions about self and social roles" (Miles 2013:63). Furthermore, due to a lack of acknowledgement and misunderstanding, sufferers can go from being 'discredited' to being seen as 'discreditable', which can be seen as a "permanent shift in character" (Miles 2013:62). 
Arguably, then, there must be a shift in understandings of sick and well, disabled and abled so as to view them as non-binary systems, creating a more fluid understanding that allows people to move closer to either end, but still retain a form of legitimacy. Theoretical frameworks such as queer theory help us to shift this understanding, as they “challenge universalizing norms that marginalize those who don't conform to hegemonic normalcy ... and engage with the lives of people who can experience high levels of discrimination, violence and intolerance" (Sherry 2004:769). Although queer theory has many overlaps with disability studies, one of its main overlaps is the deconstruction of binary systems (Sherry 2004:779). McRuer (2006), in his work on 'crip theory,' further argues that identity is not binary and that identity itself is fluid. Therefore if society in general or the medical system continually treat issues such as illness and disability that are fluid experiences as binary systems, those who do not fit into the neat categories are essentially lost from view and unable to gain legitimacy. Additionally, Sherry (2004) and Vick (2012) both argue for a move away from a binary systems of thought, to one of more fluidity where individuals are understood to not necessarily reside on either polar end, but are understood to have an identity that fluctuates from time to time and may never reach either end in its entirety.

Labels and categorization both have their purposes and problems within society; however much one might want to argue to get rid of these labels altogether, they are heavily engrained and are necessary to seek forms of legitimization and access to services. Researchers like Vick (2012) have started to problematize how we define disability/ ability and sick/well, but their needs to be more attention drawn to this in 
Canada as those who need to seek these societal labels to access assistance or care are having to fight for it or are being turned away repeatedly. Additionally, "there is a tremendous amount of stigma around disability, so disabled people are less likely to ask for what we [they] need" (Withers 2012:115). Withers (2012:115) also warns that if we leave the classification of disability in the hands of medicine and policy, the medical definitions will take precedence and those who may not 'fit' the definition will not be legitimized and will face continued barriers to care. Currently, access to many disability services requires medical acknowledgement of being disabled, which has led to organizations relying on the medical model (Withers 2012:31). The basic premise of the medical model is that "disability is a medical issue emerging from deviant anatomy" (Withers 2012:31). Besides the obvious problem this creates in labelling someone as deviant and in need of reaching 'normal,' it also places the doctors in control of access to services they have no knowledge of. Relying solely on the medical model means that ultimately "doctors can control the distribution of everything from accessible housing and transportation, workplace accommodations, mobility aids, attendant care, training and education, technology, counselling, income and food" (Withers 2012:43). This is problematic as doctors do not necessarily have the skills or knowledge base to assess these needs and can create barriers for individuals who require access to services (Withers 2012:35). Furthermore, as Withers (2012:115) argues, it is the individuals who must be allowed the space to self-identify in order to voice the specific needs and concerns they have. 


\section{Access to Care and the Dangers of Gendering an IIIness}

Finally, illness narratives can also provide commentary into how gender is viewed and treated in relation to relatively 'invisible' chronic illnesses. Lupus is known to be 90 percent more prevalent among women and includes aspects that are not relatively visible or at time quantifiable by medical practitioners. Due to this relative ambiguity of symptoms and a history of women's health issues being deprioritized, women face additional barriers to accessing the care that they require. Historically, women's health has been thought of as less important than men's and therefore in society has been sidelined. One issue that affects lupus and other chronic conditions that affect mostly women is the lack of research focus and the lack of funding. Many policies and services have been put into place over the last few decades, yet they do not always address the needs of those who require them.

For example, many programs that are set up to support those with chronic conditions focus on self-care and self-management, which often "overlook[s] the role of social determinants of health" (Pederson and Liwander 2012:47-48). Furthermore they state that, "women's needs for, and experiences of, primary care are both distinct from and overlap with those of men's, and are influenced by the context of care and assumptions, beliefs, and experiences of health care providers, not simply medical need" (Pederson and Liwander 2012:49). They argue that barriers women face when accessing health care are often ignored, such as financial stability and care providing responsibilities (Pederson and Liwander 2012:50). Similarly Delaney and Bell (2008:40) noted that "the failure to recognize that structural factors also constrain life choices and 
life chances is particularly problematic for women because patriarchal social relations frame the negotiating processes." This means that those who have the power to change who is able to gain access to appropriate care are not necessarily those who have knowledge of who requires care.

One of the main complaints of these illnesses is chronic unexplained pain, which can lead doctors to believe that the patient is a hypochondriac or attention seeking, which can delay care. This is especially true if we take into account the historical treatment of women's health complaints as being 'all in their head' (Shildrick 1997). Historically, many women who sought health care were deemed 'hysterical' and although medicine has improved throughout the years, with the invisibility of some symptoms commonly associated with illnesses that affect mostly women, the underpinnings of this thought process has not vanished (Shildrick 1997). As mentioned earlier, some in the medical field view these patients as 'bed blockers' and do not believe their experiences of pain (Devaney 2012:29). This can be especially problematic when a patient tries to tell a doctor exactly what is required, as the professionals do not see the patients as experts (Devaney 2012:102). For example, Devaney (2012:102-103), went to the ER in 2002 on the advice of her specialist to receive her medication intravenously, however, she was met with delays when the emergency doctor did not believe her condition to be that severe and decided to wait on blood test results. Inevitably she was given the medication intravenously when her results came back showing there was a problem (Devaney 2012:103). This type of incident took place several times, even though she had a specialist that was trying to advocate for her sometimes, from a distance (Devaney 2012). 
Some people who have chronic pain symptoms or chronic fatigue symptoms do not have a specialist they can turn to, thus their concerns can often be turned away until they can visibly and physically illustrate that they are ill. As Ehrenreich (1989) argues, barriers to a proper diagnosis can delegitimize a patient's experience with their bodies. Invoking Parsons' concept of the 'sick role,' she states, "you can be sick as a dog, but you don't get to enter the sick 'role' until you've paid your way through the medical system and emerged with a recognizable label" (Ehrenreich 1989:29).

Grills and Grills (2008:53) also argue that in addition to some of these complaints being viewed as attention seeking, women can also doubt their own symptoms, resulting in a delay in care. Due to the invisibility of some aspects of chronic illness, both practitioners and the general public tend to dismiss the symptoms as not being 'real' and as this becomes widely accepted in broader society, they argue that this results in women sometimes not trusting their own experiences (Grills and Grills 2008:62). Moreover, they note that doubt, "is resisted, encouraged, sustained, and made meaningful relative to and arising from relations with others" (Grills and Grills 2008:62). Arguably then, doubt of the validity of someone's symptoms places a major barrier in the claim to a diagnosis and treatment.

Focusing an analysis on female issues in health care alone would, however, fail to encompass all aspects that are involved in gendered barriers to care. As found in my own research, male participants felt marginalized by the female dominated orientation of lupus, including its most popular symbol, the butterfly, and its association with the colour purple. Research needs to consider how illnesses affect both genders even when the 
illness is more prevalent among one gender group. By failing to realize that a disease can still affect the non-dominant gender a delay in care and diagnosis can presumably result.

\section{Conclusion}

Without illness narratives, some of the above issues might go unknown or unstudied. Although illness narratives focus on the singular story of the individual, they provide insight into broad areas that affect disease progression and possible mitigating factors that can improve access to health care. Although no two narratives are exactly the same, due to shared culture and social structure, commonalities can be found. Lupus illness narratives are just beginning to be studied and as such, issues such as stigma, body image, mental health, and access to care are finally being examined. Arguably, then, although the illness narrative sets out to tell the individual story, they ultimately illustrate more of a collective voice. As more narratives are voiced and chronicled, more insight can be derived and possible avenues to ameliorate some of these experiences can be explored. Through my own interviews, in the two following chapters, I will expand on some of the themes that were expressed in previous literature and elucidate the effects that they are having on people currently living with lupus. In Chapter 3, I will discuss how social aspects of disease have had a profound impact on the informants and how these social aspects, such as stigma and issues with familial support, can affect the sense of legitimacy felt within the illness experience. In Chapter 4, I will take a slightly different approach and discuss problems associated with the care that is available to these individuals and the barriers they face in accessing services they require. 


\section{Chapter 3 - From Limitations to Stigma to Thwarted Dreams: Lupus and Social Aspects of Life}

My mother calls to talk to me about what she is wearing to her aunt's funeral.

This includes the regular questions of 'will this draw attention' or 'will this be respectful enough,' but what is different is when she states she will have to cover her hands in some way. My mother's hands have become disfigured due to severe rheumatoid arthritis and her skin on her hands is all dried, scaly and cracked as a result of lupus attacking her healthy skin cells. She feels others will look down on her for this, and so she feels the need to cover them so as not to cause other people discomfort. Although its impact on body image is one way stigma can manifest, stigma manifests itself in many forms that are compounded by both the illnesses people have, and the social experiences they encounter. Stigma is just one of many social implications that can arise from living with lupus. This chapter, by means of analyzing the narratives of the informants, aims to delve into some of the social implications of having lupus. I found that many of my informants' daily routines and lives were directly affected by having lupus. Themes included experiences of daily limitations, gendered implications, problems with support systems, social perceptions of the illness and their implications, dealing with stigma, and coping with lupus, including in some cases, dealing with depression.

\section{General Limitations on Life}

Lupus varies in expression and severity from individual to individual and goes through periods of active disease (more commonly referred to as flare-ups) and periods 
of remission. This section will start with an example of one informant's flare-ups and how much they can affect the individual. Meredith was diagnosed with lupus in 2001 when she experienced her first flare-up which came on suddenly one night when she was outside in -30 degree weather. Despite wearing gloves, two of her fingers became completely frozen and her wrist swelled. Within two weeks of this incident, she felt like her body had gone into shock and she was walking around with her mind in a fog, as if she were constantly in a drunken stupor. In 2002, she experienced another flare-up, where she felt she couldn't breathe (a symptom of pleurisy), but when she called her rheumatologist on a Monday, she could not get an appointment until the Friday. Despite the medication that was prescribed, she dealt with pleurisy for over a year. "My life was over, nothing worse than not being able to breathe," she stated quite poignantly. To this day, she still endures pain while breathing. Two years later, Meredith started to suffer from severe mouth sores, which progressed to the point where she could no longer speak without being in grave pain. Instead of taking time off from work, she brought in a doctor's note stating she could not talk and continued to work, for fear of losing her job. Additionally, she no longer has any energy after work and finds it hard to get things done, stating that she often wonders how she makes it out of bed in the morning. Notably, Meredith's experience is not unique to her, rather, I have used her as a primary example of common concerns, as she was particularly forthcoming with the details of her major flare-ups.

Lupus has also imposed various limitations on other informants, either as a constant or during times of active disease. When Adrian was first experiencing the onset 
of lupus, he noted, "I felt debilitated, during this time I'd just sleep, and then I'd go to work. I was definitely becoming anemic, so I was like whoa and then I could do nothing." Adrian must limit his exposure to many people during flu season, due to the immunosuppressive drugs he is on. Another way Adrian has been limited socially is in dating, as he is finding it hard to find a partner who is willing to accept his diagnosis, but also understands that he is independent. Another informant, Rose, like most, suffers from fatigue, but also has problems with the mobility of one of her legs which at times makes it difficult to complete everyday tasks. Additionally, Rose is afflicted with a number of secondary conditions associated with lupus, including Sjögren's syndrome, which involves constant dryness of the mouth and eyes along with dryness in other regions of the body (Fox 2005:321). Paige suffers chronically from arthritic-type pains and stated that although her symptoms have varied and changed throughout the years, as of late, her back, knees and hands have become quite arthritic when she is ill. She stated that, “When I am sick I can't even tie my own shoes, let alone hold a pencil, let alone do anything. The fatigue is just intense." Paige has not had a major flare-up in over 10 years, but goes through days when she is extremely fatigued. She noted that life is really a balance, and while she still wants to live her daily life, she must do so cautiously. Another participant, Dianna, has mainly had to deal with fatigue and joint pain, but her lupus has also affected multiple major organ systems. As a result she has kidney and heart issues, including a heart attack she endured last year at the age of 38 . This has affected her overall outlook for her future and affects how she goes about her daily activities. Breanna, an older informant, remembers dealing with frequent headaches, 
joint pain, and feeling like her brain was in a fog during her time of diagnosis. Due to an overwhelming sense of fatigue, Breanna chose to retire early and has had to cut back on her community involvement.

Another informant, lan, has been in remission for 20 years due to a round of chemotherapy, which was previously used as a treatment but has since been discontinued. However, during active disease lupus caused lan to become fatigued, causing him to lose his appetite and eventually he was unable to physically get up. Similarly, Lorelai has also been in a relatively remissive state for awhile, but during a flareup suffered from a persistent sore wrist and elbow and her eyelid became swollen. Betty deals with sun sensitivity and cannot go outside for extended periods of time. Daily she faces limitations in her hands, hips and back in addition to being photosensitive, which has led to it being a challenge to stay fit. Additionally, the chronic pain she feels daily affects her ability to get a restful night's sleep. Michelle, a younger informant, at the age of 25 suffers from chronic joint pain in her hands which has made it difficult for her to keep up in school throughout the years. Currently she is on her fourth year of a two year degree and due to fatigue is unable to hold down employment while she attends school. Finally, Sophia, at the time of diagnosis suffered from extreme fatigue, loss of appetite, hair loss and her gums would intermittently bleed. Although Sophia has been in a remissive state for a long time she still suffers from being easily fatigued and is ever fearful of another flare-up.

As is clear from the above examples, most of my informants live in some form of chronic pain or suffer from chronic fatigue while in a remissive state, however note 
worsened and more severe disease involvement during flare-ups. This has affected them both at home and at work. Meredith lives in chronic pain with every breath she takes and Michelle has to set aside time to do basic tasks, like cooking a meal, because the pain in her hands often will not allow her to do so at will. The list of ways lupus has affected these individuals' daily routines is extensive, but it also affects how they make plans and dictates what they can and cannot complete in a given day. Many stated that they feel they cannot make vacation plans or commit to many things for fear of having a flare-up. Even those who have been in a remissive state still have these fears, for lupus is a very unpredictable illness. Almost all participants expressed concern for the uncertainty of their disease progression and that they fear not being able to have a full life or feel that they are failing those around them, such as their partners, friends or children. Most care for these patients ends at the doctor's visits, while little to nothing is done to help those afflicted with the day to day aspects of dealing with lupus. As Kleinman (1988: 44) stated, "the undercurrent of chronic illness is like the volcano: it does not go away. It menaces. It erupts. It is out of control. One damned thing follows another. Confronting crisis is only one part of the picture." The impact does not end after the diagnosis and treatment starts, rather it is an ongoing process of daily compromises and sacrifices. As will be discussed further in a section below, some of these struggles and fears can turn into 'internalized' stigma and can lead individuals to compromise themselves and attempt to 'pass' for healthy, for fear of ridicule or isolation. 


\section{Informant and Public Understandings of Lupus}

The exact causation of lupus is still not completely confirmed, yet there are a few theories that have been brought forward by the biomedical system, which include predisposition through genetics, environmental stressors, and adverse reactions to antibiotic medications. Most informants described their lupus in a similar manner with slight variations, and most accurately explained lupus as an autoimmune disease, in which the immune system is heightened to the point where it starts to attack one's own healthy cells. This then causes the individual to suffer from chronic fatigue and chronic pain in varying degrees. Most informants noted the existence of common misconceptions including people associating lupus with HIV/AIDS, as it is also categorized as an autoimmune disease, which results in people attributing to it common stereotypes of disease causation and spread associated with HIV/AIDS. Another common misconception noted by informants was that lupus is a form of cancer. None were too sure why this was, but it may have to do with its periods of remission, and the fact that chemotherapy was once used as an experimental treatment.

One informant, Adrian, would dispel misconceptions and aid in people's understanding of lupus by bringing up the names of celebrities who are known to have lupus as a means of providing a point of reference. During our interview he stated that commonly he would refer to people like the singer Seal or Selena Gomez to aid him when he was explaining lupus to someone. Another informant, Sophia, uses the narrative The Spoon Theory, discussed previously in the introduction to this thesis, to aid in explaining how chronic fatigue can dictate someone's everyday life. In this narrative, a person 
suffering chronic fatigue gives a non-sufferer a certain number of spoons at the beginning of the day and states that they must cash them in to complete ordinary tasks, including things like brushing their teeth. Pretty soon into the day the person has run out of spoons and can no longer complete tasks. This, Sophia and others have found to be quite useful to explain to others how the constant fatigue affects their lives as they only have so much energy to complete tasks in a given day and often find themselves exhausted.

I would also like to call attention to the overall lack of knowledge about lupus in the general populace and the effects this has had on individuals. For the most part, even in my own everyday conversations with others, I have found the overall public acknowledgement of lupus in Canada lacking. I have found that when confronted with the question of what lupus is, most will respond with either 'I've never heard of that' or 'That's a form of cancer, right?' Throughout the interviews informants shared this sentiment, that in general, unless either afflicted themselves, or with a direct tie to a close family member living with lupus, people did not know or understand what lupus is. This has led to many not feeling comfortable with disclosing their illness to friends, or even people at work for fear of being ostracized or singled out. The sentiment was clear in all the interviews that more awareness is needed and more specifically, there is more need for media attention to lupus in Canada. One informant noted how both the British and American lupus associations have more funding opportunities and have created more awareness surrounding this chronic illness, and that Canada seems to depend on foreign research rather than producing its own. 
Explanatory models are important, as they inform us as to how individuals understand and express their own illnesses, at times in ways that can differ from the common biomedical models of the illness. Informants' explanations of their illness included descriptions of chronic fatigue and The Spoon Theory. Most would start by explaining what lupus was, but would end by explaining how it personally affects them and how it can differ for each individual. Most also noted that although there has been an increase in awareness, there is still a lack of public knowledge and many misconceptions.

\section{Support Systems and Dealing with a Lack of Support}

Familial and external support systems can greatly affect one's outlook on chronic illness, in either a positive or negative manner. For informants such as Dianna, Rose and Betty, there has either been a lack of support, or misunderstanding and ridicule by one or both parents, which has undoubtedly affected the way they view themselves and their illness. Rose, a married mother of two step-children, is not allowed to talk about her illness with her family, and is made to feel as though it is her own fault that she has lupus. She stated that this occurred for a couple of reasons, the first being that her brother died of lupus and the second being her cultural background. Rose comes from an East Asian familial background and stated that in her family, they do not talk about illness with family members, and she has even been told by her uncle not to tell some of her extended family members about her disease. Furthermore, she stated, "my family never talked about it after [my brother] died; they were ashamed or they just didn't want to 
talk about it. So when I was diagnosed I had to learn what it was and I had this stigma attached to it because of my parents' shame, wanting to just put it in the past." For Betty, a married mother of two, even before diagnosis her mother constantly called her a hypochondriac 'jokingly,' which has made it difficult for Betty to legitimize her own illness. She stated that her father had been more accepting, but that she felt he also sometimes would view her as another 'lazy teenager'. This has led Betty to overcompensate in other parts of her life. An example of this is how at work she feels the need to assert her competency and irreplaceability. In Dianna's case, as a married mother of five children, she explained that her father initially seemed indifferent to her diagnosis and did not understand why she was writing on social media as she was, which caused additional stress in her life and put a strain on their relationship. They have since been able to reconcile their relationship and her father has become rather supportive, which has aided her in developing a more positive outlook than she previously had.

Another informant who also experienced a lack of support, but not at the hands of her parents, is Meredith, a divorced mother of two. Her lack of support is the result of the continual spousal abuse she endured, which has affected her overall perspective on life. "He stole the best years of my life", she emotionally stated in our interview. No one at Meredith's work knows about her illness and during the interview we had to constantly keep watch for her coworkers, so as that they would not overhear our conversation. For the most part, not having an adequate personal support system in place has affected these individuals negatively and has led to increased 'internalized' 
stigma and a lack of a sense of legitimacy in their own illness, which has led them to feel as though they must 'pass' as normal and not disclose their illness.

Not all interpersonal experiences related to lupus have been negative, and those who have received overwhelming support from either their families or their friends demonstrated a more positive outlook, and overall were more forthcoming about their illness with work colleagues and friends. This description would apply to informants such as Adrian, Paige and Lorelai. Adrian has been able to receive the support he has needed from both his family and friends, and is now actively seeking out a partner to spend the rest of his life with. Adrian takes great pride in his life accomplishments including his stable income, his place of residence and the fact that he drives a nice car. With encouragement from both family and friends, it seems as though Adrian has been able to keep a positive outlook, despite some of the limitations that his lupus imposes on him, such as working from home, a result of him being more susceptible to air-borne illnesses due to the immunosuppressant drug he takes.

Paige has received overwhelming support from her parents, especially during the years when she was seeking a diagnosis. When Western biomedical practitioners did not have the answers or chalked up her pains to normal growing pains or the result of her being a dancer, her parents actively sought out other opinions from alternative medicine practitioners, including an herbologist, an iridologist and an allergy specialist, but at the time they still could not provide answers. Despite a lack of answers, she stated that her parents never gave up looking for them and are still overwhelmingly supportive, including getting involved with a lupus organization. This has led to Paige being open about her 
illness and has also led to the possibility of writing a book. Similarly, although diagnosed at a later age, Lorelai has only had a positive experience of support. She stated that, "I'm lucky. I've always had positive support" in reference to fellow sufferers she knows who do not have the support she has had. In all three cases where informants indicated that they have always had a positive support system, these individuals were also more open about their illness and the way it affects them with friends and coworkers, which has allowed them certain accommodations, especially in the workplace. For Adrian, he is able to work from home when he needs to, and for Lorelai, she is warned when to stay away from people that may cause her to become ill.

There seems to be a stark difference in outlooks based on the personal support that lupus sufferers are given by those who are closest to them. With negative reactions or lack of support, sufferers like Meredith and Betty think that people will view them differently if they know about their diagnosis, and they go out of their way to overcompensate for what they view as an 'inadequacy.' Positive reinforcement or support has seemed to allow the informants to be more open about their illness, and seemingly they lack a sense of anticipated stigma (which will be discussed further below). Overall, the type of support or lack of support affects how people view their illness and the ways in which they feel comfortable expressing their illness.

\section{Body Image Issues}

Although not highlighted in my original research questions, this topic became very prominent in the interviews from the beginning. Either through treatment or as a result 
of lupus itself, lupus has caused negative body image issues in several forms among my informants. The first problem is the ways in which lupus itself can affect a person's appearance. For example, Breanna, a retired informant, asked if my mother had had to deal with hair loss in any way and then informed me that she covers her hair with a wig. Similarly, Meredith had also asked me about my mother's hair, as hers had thinned out quite a bit and she struggled to keep it 'nice.' Mary has discoid lupus, a form of lupus that primarily affects the skin, therefore she has been left with some scarring and before she was receiving adequate treatment had red, irritated skin on most of her body. She has faced ridicule not only in person with people asking what is wrong with her, but also in online communities where she has posted photos, for the purpose of online dating. This has caused her to have a very negative view of her own appearance and has made it difficult for her to feel normal in everyday interactions.

Another way in which body image can be affected by lupus is through the side effects related to medical treatment. Most people with lupus have at one point been prescribed prednisone (a steroid) as treatment for their lupus. This drug, although effective, can have devastating side effects including rapid weight fluctuations due to water retention and its effects on the thyroid gland. Most informants in this study experienced this at some point. Some even had to deal with the rapid weight gain and loss during high school, like Paige, who stated, "you're up 30 pounds, you're down 65, it's hard" in reference to being on prednisone. Sophia noted she has gained a lot of weight due to the use of prednisone, but most people have assumed it is a residual effect of having her children, despite her youngest child being six years of age. Lorelai also noted 
the ill effects the use of prednisone can have on the body, while Adrian noted that while on prednisone "it made me fat and feel like crap." He also noted unexpected weight gain while on other medications, stating that it was a result of not having proper dosages of medications or his doctors experimenting with medication options. lan, although not directly affected by the use of prednisone, voiced that the disease, when active, can cause a negative view of one's body more generally, as it can be debilitating at times. Ian also stated that, "it does something with your physical self and you have mental issues," and further elaborated that some people get visible rashes or they do not look well in general, which can cause negative body image issues. These negative effects on an individual's body image have directly affected the stigma that the person experiences, internalizes and then anticipates, which will be discussed in more detail below.

\section{The Gendered Experience of Lupus}

Another theme that came out of the interviews was the effects a person's gender can have on how an illness is handled and viewed. Although most participants thought that their gender did not play a role in the treatment they received and the overall view of their illness, some had differing experiences, which I will briefly discuss. Lupus in general is commonly referred to as a woman's disease, as it affects nine times more women than men. As such, some feel that the illness is treated differently by both the public and the health care sectors due to its gendered nature. Adrian thought that the view of lupus as affecting mostly women aided in the delay of his diagnosis, as he felt the doctors were not thinking 'outside the box' in considering this diagnosis. In contrast, he 
stated that, "they take men more seriously (in the context of health), because men don't complain, so when you complain it's serious." While I agree with the first half of Adrian's statement that women's health is not taken as seriously as men's, his reasoning that it is due to greater male stoicism is riddled with sexism, which arguably is partially why women's health has been historically treated as secondary. He also noted that a lot of the resources on the Internet are tailored more for women with lupus, and he found it hard to find appropriate resources for some situations. One such resource, that he found geared only towards women, was dating advice for people living with lupus.

Two participants had similar views when it came to how lupus is regarded and treated as a woman's disease by the general public. Breanna noted that although they are building awareness through their yearly walks, it is hard to conjure up support, as she stated, "men will support men's issues, but it's hard for the women to get out to support it, as they [female supporters] usually have lupus." Lorelai, also stated that 'if it's not cancer it just gets brushed aside.' Both participants were in agreement that the awareness is hard to 'market' as lupus does not present itself in a marketable form, as something like breast cancer would. Another informant elaborated on this as she stated that, "they can't assign something sexy to it, to make a campaign." Both of these women expressed a lack of exposure and awareness of the public in regards to lupus in general, but noted that they thought that it being known as a woman's disease did not help with trying to create awareness. Michelle, who considers herself an activist, also noted discrepancies in the ways that women's health is dealt with in general. She felt that women's health is studied less than men's health. So, although some felt that there were 
no differences in the ways they were being treated personally because of their gender, there were some differing views and sentiments that were expressed with regard to the 'marketability' of lupus as a disease that could garner public support. Specifically, some felt that the gendered nature of the disease was an impediment to creating awareness and garnering financial support from the public.

\section{Fears about the Future and Thwarted Dreams}

Lupus can be an unpredictable chronic illness; even while on medications to subdue the symptoms, a person can experience a flare-up. As a result, many feel as though they are unable to plan trips or go certain places, as they do not feel safe being far away from their health care providers who know their medical history. Others have noted that they chose to not have children as they were afraid of the unconfirmed genetic tie. Some who did have children fear that their children will not remember the good about them, or will primarily remember that their mother was the one who was unable to do certain things or keep up in a certain manner. Some even feared that their children would resent them over time and have tried to compensate. Moreover, in a few cases some feared not being able to be there for their children, as they feared that their lives would be cut short. Additionally, many feared losing control over their bodies as their chronic illness affects them over the years.

Although she is alright with it now, Breanna was originally forced to claim early retirement as a result of not having enough energy to perform her job efficiently enough. She stated that, "by afternoon I'd have trouble just making it up the stairs to check my 
mail." She noted that she also has had to cut back on hosting family events as they take too much energy to complete by herself, and she has had to focus on her own health. Quite poignantly she stated, “I'm the CEO of the most important company l'Il ever work for and that's managing my life and my health ... It's the toughest job I've had." Michelle, the youngest participant in the study, also noted problems with work, but hers differed slightly. Michelle, at the time of interview, was enrolled in her fourth year of a two year program in school and stated that although in the beginning she tried to hold down employment while being in school, she was not able to keep this up. As a result, she feels that when she graduates she will have difficulty finding a job as she will not have as much work experience as others, and future employers may inquire as to why there is such a large gap on her résumé.

Dianna, an informant who has had multiple organ complications to do with her lupus, including having a heart attack and having kidney problems, fears not being there for her five children. Although she stated that she has made many health conscious changes since her heart attack and feels more confident in her future, the fear is still there, which is partially why she blogs on social media. It is not just a way of reaching out to people with chronic illness, but it is also a legacy that she wishes to leave for her children, just in case she cannot be there for them herself. She also fears that they will resent her for not being able to do everything all the other mothers can do. This is not a sentiment that is entirely her own, as Sophia and Betty also had similar worries about their own children, fearing they might be resentful because their mother cannot keep up like 'normal' mothers can. 
Betty also expressed another fear of the future, in that she fears that she will lose control over her own body over time. She stated that she is an advocate for euthanasia and hopes that if she gets to a point in her life where her own body is no longer in her control she will have the option to end her own life in the way that she chooses. Mary, another informant who has discoid lupus, also fears a loss of mobility, but for different reasons. During active flare-ups the skin on her entire body becomes scaly and very thin, leaving her unable to do many things and although this is under control currently, she fears for a time when it will not be. Currently, her lupus is being controlled with an experimental treatment (which will be further explored in the next chapter). Most of the participants did not have an overall positive outlook when it came to the future, which likely contributed to feelings of depression expressed by some. The unknown variables of lupus not only affect the day to day activities of those afflicted, but inform future decisions as well.

\section{Stigma}

Perhaps the most pronounced theme to emerge out of the interviews was people's thoughts and perceptions of stigma from family, friends, the general public and professional practitioners. Here, I will discuss how stigma felt from non-professionals has affected and continues to affect those with lupus. Stigma and other issues dealing with professionals will be discussed in the next chapter. To reiterate from the previous chapter, Earnshaw and Quinn (2011:158) differentiated between three types of stigma: 'enacted', or stigma that is experienced by the person, 'internalized', or stigma that the 
individual places on themselves a result of negative views of others, and 'anticipated', or stigma that has not happened yet, but is expected and thus results in the person avoiding things or acting in a certain manner. All three types are reflected in the stigma felt by the informants in this study.

'Enacted' stigma has presented itself in several ways throughout the narratives. One of these ways includes the negative familial views previously mentioned by Betty and Dianna. Betty experienced stigma through repeatedly being called a hypochondriac by her mother both before and after diagnosis, and Dianna experienced stigma through the lack of disease knowledge and understanding of her father. Another way in which many of the participants experienced enacted stigma was through friends who did not understand why they cannot always commit or why they sometimes have to cancel plans frequently. Such examples of 'enacted' stigma were common, and sometimes led to 'internalized' stigma.

For several that expressed sentiments that could be attributed to 'internalized' stigma, they voiced that they must overcompensate either at home, in public or at work for the inadequacies they feel they have. For example, Betty stated that she has made herself irreplaceable at work, stating that she may miss a few days here and there, but her work is far superior and preferred by her boss. Additionally Betty sometimes overcompensates with her children for the times she cannot do things and also in fear of not being there for them in the future. She also stated several times during the interview that she felt people potentially viewed her as 'flaky' and she did not wish to be so, which may be attributed to her mother's enacted stigma of calling her a hypochondriac. Adrian 
kept overemphasizing his successes, such as his job or his living accommodations, as if he were trying to make up for a lack of something. This I have taken to be an internalization of the association of not being able to be successful with lupus.

'Anticipated' stigma was evidenced in the narratives of most participants. This has affected the way in which people choose who to tell about their illness and who not to. For example, Michelle, the graduate student, is fearful of her future job prospects and being judged harshly for not being able to concurrently hold down employment while also being a student. Moreover, she feels employers may view her as a liability rather than an asset in comparison with other candidates for future employment. Meredith also experiences 'anticipated' stigma to the point where she was fearful of one of her coworkers walking into the cafeteria and overhearing our interview. She voiced that she feared they would gossip and that they would view her differently. Some of the other participants also expressed an anticipation of stigma by people whom they anticipated would view them as lazy for not being able to complete everyday tasks in a timely manner, so they sometimes try to just get them done anyways. Just as Earnshaw and Quinn (2000:245) noted in their own study, if people had experiences of 'enacted' stigma, they were more likely to have increased experiences of both 'internalized' and 'anticipated' stigma. The three kinds of stigma seem to exacerbate each other, and this has resulted in most people either concealing their illness in some fashion, or not feeling comfortable disclosing it. This has arguably resulted in most feeling that they have to appear normal, otherwise referred to as 'passing.' To reiterate, 'passing' as defined by Joachim and Acorn (2000:245), is intentional actions taken to cover an illness in such a 
way that the afflicted appears as if he or she belongs to the 'normal' group. This felt need to 'pass' has led some to have lowered views of self-worth and has resulted in issues, including depression.

\section{Depression, Psychological Impact and Emotional Coping}

As a result of stigma felt by these individuals in combination with other life events, several participants such as Ian, Meredith and Dianna have all voiced concerns about depression and have either sought or are seeking therapies to aid in this. Dianna, for example, in addition to seeking professional therapy, also employs colour therapy into her own day-to-day activities as a coping method. Meredith has sought out several professional therapists to help her cope both with her past history of spousal abuse and her disease progression. However, she stated she has not found one that has proved helpful, and she felt they were just there to collect a paycheck, rather than address her concerns. She also noted that she is limited to the therapists that her Ontario Health Insurance Policy will cover.

For others, like Breanna and Lorelai, although they have not experienced depression themselves, they expressed how common they felt it was among others whom they know that have lupus. For instance, lan, a middle-aged informant who has not had a flare-up in over 20 years, noted that during times of disease activation for him, it was like he was a 'shell of himself', and that at one point he was almost admitted to the mental health ward due to his depressive state while he was receiving hospital care for his lupus flare-up. Some informants, such as Lorelai and Paige, noted that it would be 
easy to fall into a depressive state, but they keep themselves out of it by staying active and staying socially involved. Throughout the years, most informants noted that they had dealt with depression or depressive-like states, at some point in their disease progression. Breanna stated that:

The first year after diagnosis is very difficult as you just spent the past few years realizing your life is not what it used to be, it's not what you've been planning for it to become, and so it's almost like a process of mourning who you were and not being able to figure out why it is and what you can do about it and I guess for a lot of people that's the stage that you would go into depression.

Additionally, it is my contention that some of the depression that results is directly caused by the stigma endured, as the stigma has in some ways delegitimized their illness experience and causes them to withhold their experiences from the general populace.

\section{Conclusion}

In Norma Ware's (1992) study on the delegitimization of illness experience due to the invisibility of physical markers associated with chronic fatigue syndrome, she notes that some of this deligitimization results from the commonality of some of the symptoms. These included things like being fatigued, joint pain, headache and feeling depressed (Ware 1992:350). Generally people found that when they expressed these concerns or symptoms they were dismissed as 'everyone' experiences them from time to time (Ware 1992:350). People reacting in this way, however, possibly results in the patient feeling that their illness experience is not valid (Ware 1992:352). Ware 
(1992:352) further states that as a result some patients felt that they must keep up with the expectations of 'normal' society, until they can gain a sense of legitimacy either by later developing physical signs of illness or by receiving a recognized medical diagnosis (Ware 1992:356). Although some symptoms of lupus are visible, many are not and some are only visible to people who already have a working knowledge of the illness. Many informants in this study experienced a sense of delegitimization from time to time, some more than others. For example, Betty's own mother would constantly refer to her as a hypochondriac, thus basically stating that her symptoms were imaginary and delegitimizing her experience. This resulted in her feeling like people viewed her as lazy and may have contributed to her need to overcompensate at home with her children and at work. This type of overcompensating approach has been termed the 'John Wayne approach to suffering' by M. Cameron Hay (2010:259).

In this approach, the person suffering an illness either pushes past or ignores the limitations that the ailment is placing upon their body to assume a relatively accepted level of productivity (Hay 2010:260). Hay (2010:265) noted, though, that some cannot take this avenue and as a result feel devalued. One such case of taking a 'John Wayne' approach is very evident in my own research and that is Meredith, who has had several setbacks due to flare-ups of her lupus. As stated earlier in this chapter, Meredith continued to go to work even though she could not speak due to the pain she was experiencing as a result of mouth sores. It was her fear of losing employment that led her to make this choice at the time, which arguably is the motivation to stay productive and remain as 'normal' as possible. 
Moreover, currently we reside in a society that values productivity and expects a certain level of productivity through everyday life (Hay 2010:262). This can include work, but also refers to daily tasks that take place in the home (Hay 2010:265). When an illness is not readily visible and society praises those who remain highly productive, many people suffering from illness feel that they must also take this approach (Hay 2010:266). Examples of this type of praise can be seen with Lance Armstrong or Michael J. Fox (Hay 2010:263). Although the cultural model of productivity is underpinning many of these choices, it is often a hidden cultural construct that informally informs the decision making process (Hay 2010:262). Those who are unable to remain productive, Hay (2010:269) stated, feel that they are failing to fulfill obligations of productivity and therefore suffer more as a result. Hay (2010:270) describes how one of the main differences between the 'John Wayne' approach and the 'suffering response' is agency. Some such as Michelle face physical limitations that do not allow for a choice in ignoring or overcoming symptoms, rather she is forced into what Hay (2010:266) refers to as the 'suffering response'. Michelle is unable to balance her school work, while maintaining employment simultaneously. This has resulted in her noting that she fears not finding employment and will have to face questions to answer for the large gaps in employment that are currently on her resume.

All the informants in this study were visibly 'normal', or rather their symptoms did not exhibit themselves in obvious physical manners. As a result many endured stigma from others who did not comprehend the illness experience of the individual. In these instances, especially in the case of an illness that presents invisibly, people assume a 
sense of normalcy and an expectation of productivity. Due to past experiences of stigma or societal pressures many choose to veil their illness as they do not feel they have the legitimate space to voice their concerns. Through both Hay's (2010) and Wane's (1992) work it is illustrated that the act of gaining legitimacy in illness is rather important as it gives the individual more of an agentive stance. Arguably, if people more readily recognize the limitations that illnesses involving chronic fatigue or pain place on the individual, the afflicted will not necessarily have a need to conceal what they view as their inadequacies.

Overall, having lupus has overwhelmingly affected the day-to-day lives of the informants in this study. Depending on disease severity or disease prognosis, views and thoughts can differ as to how individuals are able to cope with day-to-day activities and what their thoughts are on the future, but they do all share some commonalities. These included a call for more acknowledgement and notice from the general populace. Additionally, most voiced a concern over the lack of understanding over the unpredictability of lupus flare-ups and how this informs and ultimately controls almost every decision they make. As one informant stated, although she has not had a major flare-up in quite some time, everything must be planned in a way to accommodate for the possibility of it. In conclusion, although differing life experiences exist between the informants, they still share a number of commonalities in the way they view and deal with lupus. This discussion will be continued in the next chapter, which will deal with work place problems and issues informants have encountered in the health care field throughout their years of treatment. 


\section{Chapter 4-Barriers in Life: Lupus and Structural Aspects of Life}

Lupus can take months or years to correctly diagnose. It is the health

professional-gatekeepers in society who play a key role in the diagnosis and treatment of people living with a chronic illness. In the previous chapter, social aspects that affect the everyday lives of people living with lupus were addressed. In this chapter, I will continue a discussion of the individual and collective experience of those living with lupus, but examine more specifically encounters with health professionals, addressing issues such as access to care, and the adequacy of the care received. Throughout my interviews, informants noted the inadequacies of the care they felt they received from those who reside in gatekeeper type positions. Although some of the needs of the informants were being met, there were many others that were not. It is my contention that the provisions that are currently made available to these individuals are not adequate to meet their needs, and many aspects of care need to be reassessed to meet a growing need for accommodation and treatment. This chapter will start with a brief narrative from one informant, who has experienced many barriers in both accessing care, and receiving the treatment and accommodations she requires. Following this illustrative example, problems with accessing appropriate care will be discussed, followed by a discussion of how effective the informants feel this care was. I will then discuss problems that some are having within the workforce, and conclude the chapter with a brief discussion of episodic disability and the difficulties in claiming a disability status and disability accommodations and benefits. 


\section{Case Study: (Mary's Story)}

Mary is a single, divorced mother of three who lives on her own. She was diagnosed with discoid lupus in 2001. In addition to her lupus, she also suffers from coronary artery disease and has had two heart attacks. What makes her story a good case study and a point of departure for this chapter, is how dependent her current treatment is on her rheumatologist and the medical system in general. Mary's medical regimen includes the use of thalidomide, which has been banned in Canada for several decades due to its association with major birth abnormalities when taken by pregnant women, to whom it was marketed historically as a treatment for morning sickness. Mary receives her prescription in two week intervals, during which time she must complete a survey and a pregnancy test (even though she can no longer conceive children) to prove she is still eligible to receive the treatment. In addition to this she is reliant on her rheumatologist to fill out a similar survey and submit her test results in a timely manner so that she can retain her eligibility status to keep her prescription. Mary mentioned that although she calls and reminds her rheumatologist's office about the deadlines, which are regular, they still have sometimes not sent in the paperwork on time, which can result in the prescription being delayed and, as a result, a delay in treatment.

Mary is on this experimental treatment as without it, she is unable to do the simplest of everyday tasks; as she noted, she cannot even dress herself without enduring extreme pain and time. Mary's struggles with receiving the treatment she requires highlights several key themes that will be discussed throughout this chapter, including accessibility of care and the informants' thoughts towards their treatment by the medical 
system. Mary also had difficulty claiming disability status, a status that ultimately enabled her to be able to afford her medications and be more productive in society. She was denied twice before finally being approved with her third application. Although Mary's case is unique in some details, parts of her experience are not unique to her, and will be explored in concert with the other informants' experiences, below.

\section{Accessibility of Care}

Access to health care and the appropriate specialists is available to everyone in Canada, but the wait times tend to be long due to the prioritizing of certain conditions over others or a shortage of certain specialists. This is known to be true for many health care professions, but it is especially true for rheumatology, where there has been a known shortage of specialists for many years. Notably, all participants in this study had already been with their respective rheumatologist for a while and none were awaiting being assigned one. My method of recruitment through those who are registered with Lupus Ontario support groups may have been a limitation in this matter as each of the participants, with the exception of Michelle who was only tentatively diagnosed with lupus, had been diagnosed for two or more years. Although many participants noted that they feel they receive adequate care and attention from their rheumatology team, many noted that they know this is not always the case and have friends who have not had adequate attention to manage their illness.

A rheumatologist is responsible for the care of patients who present with over 100 different illnesses, including those that are considered rheumatic and those that are 
considered autoimmune. The average wait time to see a rheumatologist is around three months, but if the patient's case is deemed non-urgent they may be rejected or care can be delayed for even longer periods of time. Additionally, in Ontario the only way to see a rheumatologist is through the referral of a general practitioner or another doctor who is already caring for you. Some people can face years between first having symptoms of lupus and being able to access a rheumatologist for diagnosis and treatment. To draw on personal experience, my mother went undiagnosed for over ten years as her general practitioner refused to believe her complaints and would not give her a referral to a rheumatologist. Instead, she sought out a referral during the post-op appointments with her surgeon months after having a few surgeries. After receiving her diagnosis she felt legitimized, but her general practitioner still questions her diagnosis and still has not accepted it, even after he received a personal letter from the rheumatologist. I have included this small anecdote to illustrate that it is not only a shortage of rheumatologists that can create barriers to accessing care, but rather, those that act as gatekeepers to the rheumatologists can also create a barrier.

Meredith has been with the same rheumatologist since her diagnosis, but at the time of the interview just received notice that the doctor would be retiring and that she would have to seek out alternative care. She noted she does not feel that he adequately addresses her concerns, quite animatedly stating that "he looks like a corpse, but could talk though." Meredith's flare-ups range from extreme fatigue to more serious ones including a bought of pleurisy, at which time she felt like she could not breathe. This means that at times, she requires access to a rheumatologist or someone with 
specialized knowledge of lupus flare-ups, otherwise her health may decline. She stated that she was fearful of being without a rheumatologist as she knows the wait times to be assigned to a rheumatologist in Ottawa are high and some people are being turned away.

Since many cases are turned away, many feel that their illness is given little priority unless it affects one of the major organs within the body. Michelle, who has yet to receive a full diagnosis and has been told she probably has lupus, stated that, "I feel like in the case of my rheumatologist that she doesn't feel like it's a big deal unless it is in your major organs," and she furthermore stated that doctors seem to be more dismissive of the more chronic symptoms that affect the day-to-day lives of the individuals. These chronic symptoms can include joint pain and extreme fatigue that can at times become debilitating and affect the afflicted individuals' ability to function at a normal capacity on a daily basis. What may be viewed as not a severe case on paper, may be rather debilitating in reality. Michelle also noted that her rheumatologist seems to be lacking a lot of knowledge when it comes to lupus and stated that a lot of the knowledge that she has gained, she had to find on her own. Similarly, Sophia also remarked that her rheumatologist seemed to lack expertise when it came to lupus and would look to her and ask what she had found out through her own research.

Support services in the Ottawa area also include a quarterly lecture series, which is set up to be able to address questions for those who do not have rheumatologists and as a means of providing a platform for family and friends to learn about the patients' conditions. The first lecture that I attended was on a specialized topic, vasculitis, which can be a disease on its own, but it can also be a secondary disease in a patient with lupus. 
The second special lecture that I attended, was supposed to be on patient-practitioner communication and how to best prepare for your appointment. This topic had come up in an interview with a participant a few weeks prior, so I was initially excited that they were going to address this topic, but instead I was left a little disappointed. Instead of covering a broader spectrum of patient-practitioner communication they only discussed what to expect at your first rheumatology appointment. Although this is also an important topic for discussion, I felt that most people at the talk had already gone through that initial first appointment and the lecture presentation could have focused on what the doctor is looking for from the patient in a regular appointment, to make sure both patient and practitioner are able to leave the meeting satisfied. So although these public information lectures are important, it is possible that they have the potential to be much more useful in the future.

In an international study that included Canada, the US and Europe, the urgency and referral process in order to see a rheumatologist was assessed. Although the main objective of this report was to suggest a new priority referral system, several important points can be taken from this study. Fitzgerald et al. (2011:231-232) concluded "that rheumatology physician resources within Canada were inadequate to meet clinical responsibilities and academic program requirements." Furthermore, they stated that the shortage that they observed while conducting the study was expected to worsen over the next 14 years (Fitzgerald et al. 2011:232). Moreover, in a Quebec-wide study (no equivalent study has been performed in Ontario), on the wait times for a rheumatology consultation for patients presenting with rheumatoid arthritis, it was found that 34 
percent of patients received an appointment within three months, 32 percent received an appointment sometime after three months, and the remaining 34 percent were turned away (Delaurier et. al 2012:2). While neither of these studies addressed lupus specifically, they both point to the growing concern over the availability of rheumatologists. They also rely on general practitioners for referrals, who may not necessarily have the training or knowledge to recognize the multifaceted ways that chronic illnesses like lupus can present. Either due to a lack of knowledge or a lack of resources, many felt that their concerns were ignored or glossed over at times, a problem that will be explored further in the following section.

\section{Patients' Feelings about Practitioner Care}

In addition to some of the barriers faced while trying to access appropriate care, some also felt the care that they received did not always adequately address their needs. In this section I will detail problems that have been faced by my informants, first with care provided by medical professionals in general, and then by rheumatologists more specifically. I have chosen to separate the two, as although general practitioners can be expected to have knowledge regarding illness and medicine in general, rheumatologists are considered to be the experts when it comes to care for people who have lupus and other autoimmune conditions.

General practitioners and emergency room staff are often the first contacts that those who receive a diagnosis of lupus will have in the assessment of their symptoms. Some informants have received great attention from these sources, but the majority 
have not, at least on some occasions. During the time that Adrian was seeking a

diagnosis, he visited the emergency room repeatedly over a period of six months, before they assessed that something was seriously wrong with him. He reported, "I just kept going to the emergency room for about six months. I'd go to the emergency room, they'd send me home. I'd go to the emergency room, they'd send me home." Although Adrian noted that he was not, overall, dissatisfied with the care he received during this time, he thought they were not really trying to think 'outside the box,' as he is male, and also has a darker skin pigmentation, so even if he were exhibiting the symptom of a malar rash (butterfly-like patterned rash) across his face that is commonly associated with lupus, it would have been harder to detect.

Similarly, Paige, who was diagnosed at the age of 13 after her hairdresser suggested she be tested for lupus, dealt with doctors who had a hard time finding the correct diagnosis due to a tendency to blame her symptoms on other things. Like Adrian, she felt that the doctors were not completely dismissive, but rather, that they were just focusing on treating the symptoms rather than finding an underlying cause. She was a dancer at the time and a lot of her symptoms were brushed off as being a by-product of her dancing activities. At the time, they gave her a list of possible exercises to strengthen her core muscles, as they thought that might be the root of her joint and back pain, however, they neglected to recognize that with her strict dance regimen her core was already pretty strong. Moreover, she noted that through her own experience and through working around people in the medical profession, she has found that general practitioners tend not to be able to answer questions about lupus and pass all inquiries 
off to specialists. Furthermore, she stated, "it's off-putting as a patient to be talking to a doctor and still hear 'I don't know.'" Additionally, she appreciates that lupus is an illness that manifests differently from patient to patient, but believes that, "if a patient comes in with a range of symptoms then they should seriously look at it." In Paige's case, because she was so young at the time of symptom presentation, she felt that many of her complaints were overlooked and doctors mainly viewed her as a 'whiney' child.

Although Dianna's case is different, like Paige, she felt that in the beginning the doctors sought to treat the symptoms, but made little to no effort to find a cause. She stated, however, that, "because we don't know what causes lupus, I can't blame anyone and sometimes I want to blame someone, because it sucks and I am angry," in regards to how she felt towards the doctors. For her own general practitioner, she stated that her doctor acknowledges that the symptoms are not just manifestations in the patient's head, but still, she does not know much about lupus. Dianna, who also suffers from diabetes, noted that many professionals seem to prioritize the diabetes aspect of her health, overlooking that she also has lupus. She did note that her dentist offered her antibiotics before she underwent a procedure as a precautionary measure, but noted that they still seemed more concerned about the diabetes element of her health.

Betty stated that the care she received was at times good, but at other times it was not what it should have been. When her family doctor first suspected that she had lupus, he handed her a pamphlet and sent her home, simply informing her that he would see her in three weeks. She received another pamphlet in the mail from her doctor that informed her that she may never be able to conceive children-a rather impersonal way 
to receive emotionally-charged information. In another instance, she was prescribed the drug cytotec at the age of 17 and was not informed of the risks associated with the drug at the time, as it is known to cause spontaneous abortions. Many of these instances happened at the start of her treatment course, in the 1990s. She notes that doctors today seem to have a better understanding of lupus as there is more research being completed.

Although the above seems a bit discouraging, some did have positive experiences with their general health care team. Michelle, the youngest of my informants, felt that key information was lacking both in the general medical sphere and in the rheumatology sphere. She also stated that much of what she has learned she learned on her own. Importantly, though, she did note that her family doctor did seem to give her more information than her rheumatologist. She still, however, feels somewhat dismissed in general and stated that in the case of her rheumatologist, the physician tends to gloss over cases that do not involve major organs as they are deemed to be not as important. Moreover, she thought that doctors are dismissive of the more chronic symptoms and wishes that more information would be provided on how to maintain a positive quality of life.

In the case of rheumatologists, about half the informants in this study felt that they had formed a good relationship with their respective rheumatologists and that in general, their needs were being met. Some, however, similar to Michelle, found that they were lacking information and that that the physicians seemed to rely on the knowledge the patient had gained from her own research. Sophia and Breanna suggested that the 
reason for this is that $15-20$ years ago they did not necessarily teach that much about lupus in medical school. Thus, if a rheumatologist or general practitioner has been in practice for awhile, he or she may not necessarily know as much as those that are receiving their training now. Lorelai stated that although she has had a great relationship with her rheumatologist, this is not the usual case from her experience, and she has heard countless accounts of concerns being brushed aside.

One informant detailed some of the care she felt was inadequate and dismissive on the part of her rheumatologist. Dianna stated that, "the first time I saw my rheumatologist, I was there for six minutes, told I had fibro [fibromyalgia], given a prescription and told to leave." At the time she said she was not surprised by the dismissive treatment, but was still angry and upset about it. Notably, she stated that she made the mistake of not being prepared enough to speak on her own behalf, and she never challenged him for more information, so she left with none. At this appointment she was prescribed Lyrica and about half way through her prescription, she went back to see the rheumatologist as she was having difficulty functioning on the medication. She noted that this time the appointment lasted for around seven minutes, but she was simply told that she would eventually get used to the medication and to continue its use. Dianna informed me that even at half a dose, she was having a hard time functioning, and it took a lot of effort just to move her body in any deliberate movement. Adrian also noted having trouble with prescription medications and stated a few times during the interview that the rheumatologists needed to become more aware of what dosages of medications are effective for treatment, as he noted that he was sometimes prescribed 
medication on a trial and error basis. Paige, the informant who was diagnosed at the age of 13 , was actually referred to a rheumatologist when she was eight years old, however, they were unable to diagnose her. Similarly, Rose's rheumatologist apparently suspected she had lupus, but sent her home without a diagnosis. Only when her flare-ups worsened to the point of taking a trip to the emergency room did she learn of her diagnosis, but through the emergency room doctor, rather than the rheumatologist.

Most informants agreed that in order to receive the care that they required they had to work diligently with their rheumatology team and general practitioner to ensure that they were getting the most out of their treatment. Notably, those who took this approach felt more comfortable with the care that they were receiving. In particular, Dianna was quite adamant that the patient must be her own advocate to receive the needed care. Moreover, she stated that doctors are limited to short periods of time with patients and if a patient is aware of the exact information that the doctor requires and comes prepared, their appointment will be more beneficial and they will feel more in control of their illness. Breanna and Paige also emphasized assembling a health care team that the individual feels comfortable working with and that has enabled them to overcome certain aspects of their illness. This included Paige weaning herself off of medications during the course of her pregnancy. Notably this would not be possible for all those who have lupus as they may not have the resources to be able to self-advocate. Those with less education or lack of accessibility to adequate resources would presumably not be able to take on this role and as a result they would be severely disadvantaged in trying to manage their illness. Although she is able to now, Mary at one 
point was not able to afford her medication and as a result her condition worsened making it impossible for her to return to work, which perpetuated her problem of not being able to afford her medication. As much as some would assume an improved communication between patient and practitioner would improve patient care and disease manageability, this assumption seems to ignore those who may have other barriers to surpass in order to receive even minimal care.

As evidenced between the differing views brought forth by informants, communication is a key element in the overall satisfaction with care received from any medical practitioner. If the communication is good between both parties then they seemed to have an improved sense of independence, however, this is hindered and sometimes difficult with rushed appointments becoming more and more frequent and the lack of available rheumatologists to choose from. For some, they feel happy just being assigned to a rheumatologist regardless of the lack of attention as they fear not having any support, which is the case for many who are having trouble getting an appointment as evidenced in the last section that dealt with accessibility issues. This availability, although hindered within the city, would presumably be even more evident in more rural areas where there are less options for medical providers. In Canada, an average appointment lasts for 15 minutes or less, thus there is a tendency to focus on the symptoms presented at the time without looking at the cause behind the symptoms (Cazdyn 2012: 18). Additionally, in the time it takes to gain an appointment, symptoms can disappear, so without proper communication from both the patient and the practitioner, opportunities can be missed for treatment and sometimes, earlier diagnosis. 


\section{Chronic Illness in the Workforce}

Another professional sphere where those with chronic illnesses face difficulties is in their employment, and the restrictions on accommodations that are provided to them. Five of my informants did not have current employment at the time of the interview, as one was on maternity leave, one was retired, two were students, and one was in between jobs. Of the remaining nine informants, all but one worked at a full-time job. Regardless of current employment status, many had run into problems at work or feared retribution from their employers if they disclosed their illness status. As a point of departure for this topic, it is worth noting that the one informant who was retired, was forced into early retirement, as she was no longer able to perform her job. Breanna stated that "by afternoon I'd have trouble just making it up the stairs to check my mail." As illustrated by this case, many jobs can be physically or mentally demanding, and having a chronic condition such as lupus can hinder job performance and ability, especially without accommodation. Breanna chose to retire early as a result of her diagnosis and the progression of her illness, but this is not always a feasible option for those who are diagnosed at earlier points in life.

One informant who was particularly concerned about not having her coworkers and employer find out about her lupus, was Meredith. Even at the start of our interview she was concerned that one of her coworkers might walk into the eatery we were in and if they were to do so, we would have stopped the interview. Meredith stated that she has worked hard to be in the position she is in at work, and does not want to jeopardize that, so she keeps her complaints and her suffering to herself. Additionally, as mentioned 
previously, Meredith's response to extremely painful mouth sores was to bring in a doctor's note stating she could not talk, and continued to work in fear of losing her job. She is also fearful that people will spread rumours and talk about her in a negative manner. When Meredith gets home from work she has very little energy left as a result of the effort she puts into her job. Betty, like Meredith, has worked hard to earn the position at her job that she currently has. Although her boss knows about her diagnosis of lupus, she noted that she overcompensates at her job and makes it so that her work is always of superior quality, so that she is seen as an asset rather than a liability.

While some are fearful of losing their jobs, Michelle, a graduate student, is fearful of not being able to find employment after she graduates. She is currently in her fourth year of a two year program and is not entirely sure of her graduation date as of yet. She tried to hold down part-time employment, but was unable to balance work and school with being chronically tired, therefore she has a large gap on her résumé. It is this gap that she is worried about, as she does not want to immediately disclose that she has a chronic illness when she is looking for work, but feels that they will question her as to why she has such a large gap on her résumé. Mary, the informant whose narrative served as a starting point to this chapter, also faced a few challenges with employment over the years. At the time of the interview, she had just recently had the chance to start working again as she had been off recovering from a broken arm and her second heart attack. She noted that she had already had to miss a few days due to her chronic fatigue, which she was brought into the office to discuss with her employer. Initially, she felt that they were going to try and discipline her for missing more than the allowable sick days, but that 
conversation was quickly circumvented when she reminded them of her condition and offered to bring in a doctor's note explaining her illness.

Other informants felt that their employers and coworkers did a good job of trying to be accommodating as well as trying to provide aid when needed. Lorelai, who works in a health care setting, faces the challenge of potentially coming into contact with a number of airborne infections, which she is more prone to, as she is being treated with autoimmune suppressants. Her coworkers are aware of her condition and will sometimes warn her away from going near certain rooms that could potentially make her ill. Even with these helpful precautions in place she still does come into contact with potential hazards to her health. Additionally, she is finding that the full-time hours that she keeps are becoming increasingly hard to keep up and she finds herself very exhausted at the end of the day. She wants to switch to part-time, but will lose her extended medical benefits if she does, and fears that they would not approve her medical coverage if she were to try to switch back to full-time later, as she would then have a pre-existing condition.

Paige, like Lorelai, found that her coworkers were willing to accommodate her needs and were very understanding, but noted that her boss would only provide accommodations if it was provisioned or required by the union contract she was under. Adrian has also found that his employer has been very accommodating and is able to work at home, which is especially important for him during cold and flu season. For the majority of others, they have chosen not to disclose their health status at work for fears of being ridiculed or thought of as less of an asset. Those who feel confident in how they 
are viewed and accommodated at work seem to be in the minority. From the above examples, it is clear that although some places of employment are accommodating, there remain a lack of needed provisions for those with chronic conditions, which often include extreme fatigue.

The implications of episodic disability will be discussed more specifically in the next section of this chapter. However, it deserves mention here due to its relevance for difficulties faced in the workplace. Episodic disabilities are defined as chronic conditions which are marked by periods of relative good health (remission) and periods of heightened disease activity (flare-ups). These conditions can include lupus, multiple sclerosis (MS), arthritis and some mental illnesses. Research on how Canada is dealing with these types of conditions in the workforce is limited, however, a commentary published by The National Journal of Human Resource Management offers some insight. The author advocates for the inclusion of people suffering from episodic disabilities in the workforce, since the labour force in Canada is shrinking (Silliker 2012: 1). The article, which focuses on Scotiabank and the policies and adjustments it has made, makes several suggestions of how people suffering with these conditions can be easily accommodated. Moreover, it states that one of the biggest problems faced amongst workers is education and knowledge of episodic disabilities and how they might affect coworkers (Silliker 2012: 19). Although accommodations can be provided, such as flexible work hours and specialized equipment, many do not feel comfortable accepting these as they would then face resentment from coworkers who do not understand why they were receiving special considerations (Silliker 2012:19). This article seemed to echo many concerns that were 
noted by the informants in this study, who were fearful of disclosing their status. Many did not wish to be singled out or given special treatment as they were fearful that they would be talked about and resented. Therefore, it would seem that before accommodations can be offered, people need to become more aware of how these conditions can affect the lives of those who are afflicted. Without this awareness, most would not seek out accommodation for fear of ridicule and misunderstanding (Silliker 2012:19).

Margaret Vickers (2001a:64), an academic and sufferer of multiple sclerosis, has written extensively on the subject of what it means to work with an invisible chronic illness. She stresses in most of her work, in particular the difficulties faced by women with invisible chronic illnesses. She notes that women already face difficulties by virtue of the patriarchal context of the workplace. Furthermore, she states that "the medical profession are similarly influential on the mid-career woman's life - especially her working life - via its power to diagnose and discredit" (Vickers 2001a: 64). She further states in this article that due to the invisible nature of these conditions until they have a formal diagnosis, which can take a prolonged period of time, employers tend to delegitimize women's complaints until there has been a formal diagnosis (Vickers 2001: 68). Although in some instances disclosure of illness may enable the person to seek accommodations, as noted in my own study, many were reluctant to do so out of fear of stigma. Vickers found this to be similarly true in her own work, stating that, "unfortunately it seems unlikely that sufficient trust routinely exists in most workplaces, certainly not enough to encourage a voluntary workplace disclosure of a stigmatising 
invisible illness" (Vickers 2001b:84). Vickers states that within the workplace "people with unseen chronic conditions are encouraged not to be sick. They are expected to be and assumed to be 'normal', 'happy' and 'healthy'. Paradoxically, being part of a 'sick' organisation, one that encourages people to 'keep up', to fit in and be 'normal', may make them even more sick" (Vickers 2001b:111). Evidenced by Vickers', Silliker's and my own studies, it can be concluded that even if provisions were to be made more readily available, more widespread knowledge and education about conditions such as lupus is needed. If this does not occur, those who fear facing stigma by coworkers still may not seek accommodation for fear of ridicule from coworkers who will not understand why they are receiving special treatment.

\section{Episodic Disability}

Although most informants in this study did not identify as disabled, there were a few who did. For the three informants who did self-identify as having some form of disability, one (Michelle) stated that she is just coming to terms with self-identifying in this manner, but noted that she does have difficulties completing tasks due to pain or limited use of her hands. She is currently working on her master's degree and has not filed any applications to claim disability from any government entity. To be able to claim or gain an official disabled status with all government entities would enable people with episodic disabilities the ability to have access to more services, that would help them financially or physically. Currently every assistance program in Canada has their own criteria and definition of what it means to be disabled. So although they may be 
successful with one claim, they may not with another organization. The other two informants, Betty and Mary, have both applied for disability and received approved statuses from the government programs, which they received with varying degrees of difficulty. Betty did not detail if her disability status was hard to obtain or which program she applied to, rather she just stated that she had obtained it. This was, however, not the case for Mary, as she was denied the first and second time she applied, before finally gaining disability status on her third attempt with the Ontario Disability Support Program, which is also discussed by Vickers (see below). For Mary, gaining this status and being approved for assistance meant that she could afford to fill her prescriptions and continue her treatment. Although she has had a few setbacks with other health complications, this enabled her to be able to return to work, as the medication she takes enables her to be able to function in a productive capacity.

In a study conducted by Andrea Vick and Ernie Lightman (2010:76), they found that "the reality that disability affects people in different ways and that individuals with the same disability may have differing needs across different times remains unacknowledged in the actual translation of workfare programs and policies." In the current system, disability within Canada for the purposes of official claims, is conceived as suffering from a constant physical or mental ailment (Vicks and Lightman 2010:78). Little to no provisions have been made to include those who occupy an in-between state between able bodied and disabled, that is, those whose disability would be considered episodic (Vicks and Lightman 2010:78). At this current moment in time, like Mary, those with episodic disabilities have a hard time filing for disability support and must assert that 
their illness causes enough of a consistent impairment to be eligible for assistance. For chronic illnesses like lupus that are characterized by unpredictable flare-ups, this can sometimes be difficult to prove. According to Vick (2012:50), a program such as the Ontario Disability Support Program (ODSP) requires that individuals meet three major criteria. The first is that they must prove that the physical or mental impairment is continuous or recurrent enough and will last for more than a year (Vick 2012:50). Notably for lupus, flare-ups are very unpredictable and symptoms can vary from flare-up to flareup, making it a difficult task to meet this narrow criterion. This may be a factor in why Mary's application was turned away multiple times before being approved. As noted, most participants in this study did not self-identify as having a disability, but it is still imperative to note the difficulties that they may encounter should they choose to seek support in the future. Although not all cases of lupus are as debilitating as others, having access to programs, such as the Ontario Disability Support Program, can mean the difference between being able to afford to continue treatment or not, as was the case with Mary. All the other informants in this study had access to financial and familial support in some form, however, this would not be the case for all those who have lupus, thus without access to services like those outlined above, some individuals may not be able to access the care or resources they need to continue their treatments.

\section{Conclusion}

As medicine advances and technology changes, people are living longer and are surviving longer with more conditions that are chronic, including lupus. As the 
technologies have progressed, it would seem that policies and practices still have not caught up to where they need to be, to adequately meet the needs of those affected. Currently there is a shortage of specialists dealing with lupus on a regular basis, and this has had implications for the care and progression of the disease. People living with lupus face many barriers to accessing the accommodations or care that they require. Western society is designed in a way that demands people stay productive, however, with so many barriers in place to access the appropriate tools, it not always possible to do so. In several studies conducted in the United States and abroad from 2007-2014, it is evident that there is a growing trend of lupus patients who become unemployed at some point within the first 13 years after diagnosis. In one study, Yelin et al. (2007:56) note that "work loss accounts for the majority of the economic costs of illness." This means that due to a lack of support during the early stages of disease, people are not able to retain their employment and therefore become more reliant on social assistance (Yelin et al. 2007: 62). Furthermore, Yelin et al. (2007:62) add that due to early onset of lupus, many individuals will end up losing out on approximately 20 years of work, thus placing individuals at a much higher risk of poverty.

Another study, published a year later, focused on amalgamating previous research that had been conducted in various parts of the world on how having lupus affected employment and disability rates. Through their review it was found that those who were unable to work suffered personal costs, such as "[the] loss of self-esteem, limited opportunity to socialize with others, diminished ability to support dependents and to accumulate assets for retirement, limited access to employer benefits such as 
health insurance and pension plans, and decreased ability to perform non-labor market activities such as housekeeping and childcare (Scofield, Reinlib, Alarcon and Cooper 2008:1479). Some of these personal costs were seen even within my small set of informants, especially when it came to non-labour market activities. Many felt that they were not able to keep up at home or that they were not able to be there for their children in the capacity that they wished to be. In another instance, Lorelai although otherwise gainfully employed, expressed concerns of losing her health coverage if she were to reduce her hours as a means of reducing her stress. Via this study that addresses various parts of the world, it seems evident that some of these concerns are becoming more universal.

Another recent study notes a correlation between the inability to work with other factors, such as a lower education level, being relatively young at diagnosis and high rates of comorbidity (Al Dhanhani, Gignac, Su and Fortin 2009:382). Of their 432 participants, 23 percent of these individuals were unable to work and 19 percent claimed to have had to make this claim within the first five years of diagnosis (Al Dhanhani et al. 2009:382). Claims like this can be seen with informants, such as Breanna who had to retire early as she was having difficulty performing everyday tasks. Other informants, although they did not retire, either plan to or have taken on a reduced number of hours at their occupations. As stated in Drenkard et al's (2014:878) study, "even if a lupus patient continues working, lupus flares, organ damage, or poor health can diminish productivity, contributing to the risk of permanent disability." An example of this within my own informants' narratives, can be seen with Mary's disease progression and her pain in the 
simple necessary act of breathing. Throughout the years she has not been afforded the opportunity to take a leave of absence as she was trying to provide for her family, however, as a result by the time she gets home she does not have the energy to do any household tasks. Of the 511 patients included in Drenkard et al's (2014:878) study it was found that 53 percent of participants switched their duties at work to accommodate their needs, 49 percent reduced their workload or hours worked and 27 percent had had to take a leave of absence of greater than two months. Through this study it is concluded that people with lupus were four times more likely than the general population to face unemployment (Drenkard et al. 2014:885). Moreover they found that over 50 percent of participants over 40 years of age were unemployed (Drenkard et al. 2014:885). By means of conclusion, they call for better disease control and increased management of symptoms as a way of decreasing the number of people with lupus who are unemployed (Drenkard et al. 2014:885). Currently, though, there are not enough resources available in Canada to adequately address the issue of unemployment in the manner that is suggested. First, the issue of the availability of appropriate and adequate care would need to be addressed before an increase in the management of symptoms can occur.

Currently, to receive an appointment with a rheumatologist within a reasonable amount of time, first the severity of the lupus must be assessed, and if it is deemed to not be severe enough, the patient may not receive an appointment until a time at which their illness worsens. Although healthcare is meant to be universal in Canada, it seems evident that it is not necessarily the case as many face barriers in accessing this care (Harrington, Wilson, Rosenberg and Bell 2013: 147). Canada's healthcare system is set-up 
to be accessible to all regardless of wealth, however, it fails to address other barriers that may prevent people from accessing necessary services. Furthermore, in addition to availability of specialty care as noted amongst informants of this study, people also experience barriers associated with travel costs, language and costs associated with being relatively new to Canada (Harrington et al. 2013:147). Furthermore, "the daily circumstances in which people are born, live, work, and age cause health inequalities ... [and] these inequalities are influenced by 'structural drivers' - inequalities in power, money and resources" (Edwards and Cohen 2012: 152). Although these inequalities may not have been a factor in the access to care of my informants, these additional barriers to health care are in place for many people across Canada.

Additionally, when patients eventually do receive an appointment, the time is limited and does not necessarily meet the needs of the individual. An example of this is Dianna's seven minute appointment where she received a diagnosis of fibromyalgia and was promptly sent away. Without better communication between patient and practitioner, care will not improve, but without time allotment to the patients that do get referred, care will also not improve. As the number of people with chronic conditions such as lupus increases, there seems to be a necessity for the definitions and the services available to those who are afflicted to reflect the increase, yet this does not seem to be happening. Without any changes, the barriers that some of the informants dealt with will continue to affect care and overall quality of life. It is those who are in these gatekeeper type positions that need to be focused on, if these barriers are to be overcome in the future. 


\section{Chapter 5 - Conclusion}

At the outset of this endeavor, I set out to look into the narratives of those who are living with lupus in an attempt to shed light on some of the issues they face on a daily basis and the additional barriers they face as a whole. My mother's own struggles spurred me to want to explore other individuals' struggles with what I felt was a widely ignored and complicated illness. Every individual who has lupus faces different symptoms and therefore different challenges each and every day. With its unpredictability of flares, lupus, even in a relatively remissive state can cause stress and fear of an unknown future. While in a remissive state, people living with lupus also deal with daily complications such as chronic fatigue and chronic pain, so although their illness is deemed under control, they still face limitations on a daily basis. Through this research, I met many different, and at times impassioned individuals who felt compelled to share their experiences with me, as they wanted their voices and experiences to be heard. It is these daily and larger struggles that I hoped to highlight as a means of bringing more awareness to what it is like to live with an unpredictable, and relatively socially unacknowledged, chronic illness.

The challenges of living with lupus have changed in the past few decades and it has to an extent become more manageable, however, this is limited to the management of major symptoms, and little to nothing is done for the daily problems that accompany lupus. Arguably, the Canadian health care system is designed to focus on the acute rather than the chronic, which results in prolonged diagnostic periods and delays in treatment. Due to better and more accurate medical technology, the diagnosis of chronic conditions, like lupus, has increased. Although not every individual in this study faced the same 
obstacles or faced them to the same degree, together their narratives point to inadequacies that are felt by many. In this final chapter I plan to reiterate some of the arguments made throughout the previous chapters and elaborate on how they are affecting people living with chronic illnesses today. I will also comment on how this research has added to a growing knowledge base, and finally, I will provide some suggestions for further research.

In the second chapter, the issue of achieving legitimacy as 'sick' and being able to claim this status is discussed in relation to Talcott Parsons' (1951) concept of the 'sick role'. In order for people to access the 'sick role,' they must fulfill certain criteria. These criteria include that they must work towards becoming well again, with the end goal of becoming productive citizens. If they cannot necessarily become well again or are unable to be productive, then this goal is not as obtainable, and therefore they are unable to claim a certain level of legitimacy. As evidenced in other parts of this thesis, this claim to legitimacy is further complicated by the relative invisibility of most of lupus' symptoms. Even if some of these symptoms are visible, they may only be visible to those who have a working knowledge of the condition. Thus, to most people the sufferer looks relatively normal, and is expected to perform to a normal capacity on a daily basis. As a result, some feel the necessity to conceal their illness and still be productive, ignoring the physical cost to themselves in the process. They act in this manner as they feel they will be looked down upon or ridiculed by others for their lack of productivity, due in part to their lack of a claim to a 'sick role' that is recognized by society. 
Some scholars, such as Norma Ware (1992) and M. Cameron Hay (2010) have started to discuss the implications that the delegitimization of the illness experience has for the individual and the ways in which people respond culturally. Most of these types of studies have been conducted within the U.S., which while culturally similar to Canada, differs in the services that are offered and the ways in which these services are accessed. My aim is to start a discussion of some of the barriers that people with lupus face within the health care system in Canada. My research, however, was limited to Ottawa, Ontario and therefore excludes those living in more rural or remote areas, which may have fewer options for accessing care. Another limitation of my study was the range of participants accessed. All of my participants were recruited through the Lupus Ontario network, so unless they had previously reached out for support from this organization, I did not have access to them. Although the socio-economic status of participants did vary slightly, for the most part they were able to afford and gain access to the resources they required, which is not necessarily representative of the broader society, or rather those who may not have financial support or access to support resources.

With these limitations in mind, I have nevertheless started to highlight some of the daily struggles and barriers that those suffering with lupus face in general, and in Canada, specifically. Lupus is still a chronic illness that is not widely known or acknowledged by the general public and as a result people are suffering stigma due to a lack of understanding and acknowledgment of the limitations it can pose on the person's life. Medical professionals seem to be gaining greater knowledge about lupus over time, however, there still seem to be many gaps in this knowledge. More general practitioners 
have started to have a working knowledge of the illness, but with the increase in wait times to make an appointment and the decrease in time actually spent with physicians during appointments, only the symptoms present at the time of the appointment are typically focused on. As called for by some of the informants in my study, more knowledge on how to increase patient-practitioner communication is needed.

Although not always apparent, many participants felt the need to emphasize how well they were able to deal with their lives and would note that they know this is not always the case for others. Other participants would actively try to hide and conceal their ailment from others, as they did not want to face the consequences of people not understanding or treating them differently either at work or at home. Those that seemed to be most in control expressed having a strong support system in place, both in personal relationships and with their medical team. More and more people are being diagnosed with conditions such as lupus that are hard to diagnose and variable in symptom presentation. With this in mind, it might be expected that there would be an increase in the resources available and the public knowledge of such conditions along with the increase in diagnosis, however, this does not seem to be the case. Arguably, even if the definitions of who can and cannot access certain resources, such as the Ontario Disability Support Program, were changed, without public acknowledgement of the legitimacy of relatively invisible illnesses, people will still feel stigmatized and not necessarily access these resources.

Although the purpose of this thesis was to explore the narratives of those living with lupus, there are several other avenues of research that need to take place in order 
gain more knowledge and to increase the support systems that are currently available. I propose that further research needs to involve those who are not as easily accessible, such as those living in rural areas that may live a fair distance from their medical team and those who may not have the financial stability to seek out networks such as Lupus Ontario. If such people's experiences were studied, it is likely that additional barriers to care would be highlighted and the emphasis on certain elements of stigma would shift. Additionally, future research needs to be conducted on the growing shortage of rheumatologists in Canada and abroad and how this may be remedied. Similarly, research into the working knowledge that both general practitioners and rheumatologists have of lupus would be valuable, as many pointed out that there were a lot of gaps in knowledge in both professional practices.

Unless there are changes to the services that are available to those who are living with lupus or other invisible chronic illnesses, the future experience of lupus will likely remain the same as it is now. This is not necessarily inevitable, though, as every year individuals are striving for more acknowledgement and are coming up with ways to increase awareness of lupus. This, however, is not enough to address the challenges that each individual faces, and unless policy changes take place some services that are a necessity will remain relatively inaccessible to a growing population that needs them. Workplaces have only just begun to start to acknowledge the concerns of those who are living with conditions like lupus. If this acknowledgement was to continue to increase, then arguably those living with these conditions would be able to remain employed without having to also, at the same time, work at concealing their illness. 


\section{Works Cited}

Al Dhanhani, A., Gignac, M, Su, J. and Fortin, P.

2009 Work Disability in Systemic Lupus Erythematosus. Arthritis \& Rheumatism (Arthritis Care \& Research). 61(3): 378-385.

Bernard, H. R.

2006 Research Methods in Anthropology: Qualitative and Quantitative Approaches (4 ${ }^{\text {th }}$ edition). Altamira Press: Lanham, MD.

Cazdyn, E.

2012 The Already Dead: The New Time of Politics, Culture and IIIness. Duke University Press: Durham, NC.

Charmaz, K.

2010 Studying the Experience of Chronic Illness through Grounded Theory. In New Directions in the Sociology of Chronic and Disabling Conditions: Assaults on the Life World Graham Scrambler and Sasha Scrambler (eds.). Palgrave Macmillan: Basinstoke, Hampshire. Pp. 8-36.

Delaney, M. and Bell, S.

2008 The Complexities of Negotiating Power under Conditions of Chronic Illness. In Dissonant Disabilities: Women with Chronic Illnesses Explore their Lives. Dianne Driedger and Michelle Owen (eds.). Pp. 29-40.

Delaurier, A., Bernatsky, S., Baron, M., Legare, J. and Feldman, D.

2012 Wait Times for Rheumatology Consultation: Is Rheumatoid Arthritis Prioritized?. Journal of Clinical Rheumatology. 18 (7): 1-4.

Devaney, J.

2012 My Leaky Body: Tales from the Gurney. Goose Lane Editions: Fredericton, NB.

Devins, G., Edworthy, S. and ARAMIS Lupus Models Research Group

2000 Illness Intrusiveness Explains Race-Related Quality of Life Difference Among Women. Lupus, 9(1); 534-541.

Drenkard, C., Bao, G., Dennis, G., Kan, H., Jhingran, P., Molta, C. and Lim, S.

2014 Burden of Systemic Lupus Erythematosus on Employment and Work Productivity: Data From a Large Cohort in the Southeastern United States. Arthritis Care \& Research. 66(6): 878-887. 
Earnshaw, V. and Quinn, D.

2011 The Impact of Stigma in Healthcare on People Living with Chronic Illnesses. Journal of Health Psychology, 17(2): 157-168.

Earnshaw, V., Quinn, D. and Park, C.

2011 Anticipated Stigma and Quality of Life among People Living with Chronic Illnesses. Chronic Illness, 8(2): 79-88.

Edwards, N. and Cohen, E.

2012 Joining up Action to Address Social Determinants of Health and Health Inequalities in Canada. Healthcare Management Forum. 25(3): 151-154.

Ehrenreich, Barbara

1989 Sick Chic: Why Can't You Ever Find a Good Disease When You Need One? Ms. (January/February): 28-29.

Fitzgerald, A., De Coster, C., McMillan, S., Naden, R., Armstrong, F., Barber, A., Cunning, L., Conner-Spady, B., Hawker, G., Lacaille, D., Lane, C., Mosher, D., Rankin, J., Sholter, D. and Noseworthy, $\mathrm{T}$.

2011 Relative Urgency for Referral From Primary Care to Rheumatologists: The Priority Referral Score. Arthritis Care and Research, (63)2: 231-239.

Frank, A.

1997 The Wounded Storyteller: Body, Illness, and Ethics. The University of Chicago Press: Chicago, II.

Fox, R

2005 Sjögren's Syndrome. The Lancet, 366(9482): 321-331.

Gillani, F.

2013 Lupus: My Constant Companion and Greatest Inspiration. Amazon CreateSpace

Goffman E.

1963 Stigma: Notes on the Management of spoiled identity. Simon \& Schuster: New York, NY.

Gordan, P., Feldman, D., and Crose, R.

1998 The Meaning of Disability: How Women with Chronic Illness View their Experiences. Journal of Rehabilitation, 64(3): 5-11. 
Grill, S. and Grill, S.

2008 The Social Construction of Doubt: Women's Accounts of Uncertainty and Chronic Illness. In Dissonant Disabilities: Women with Chronic Illnesses Explore their Lives. Dianne Driedger and Michelle Owen (eds.). Pp. 53-62.

Hale, E., Treharne, G., Norton, Y., Lyons, A., Douglas, K., Erb, N and Kitas, G.

2006 'Concealing the Evidence': The Importance of Appearance Concerns for Patients with Systemic Lupus Erythematosus. Lupus 15(1): 532-540.

Hanna, B., Holdeman, N., Tang, R. and Schiffman, J.

2008 Retinal Toxicity Secondary to Plaquenil Therapy. Journal of the American Optometric Association, 79(2): 90-94.

Harrington, D., Wilson, K., Rosenberg, M. and Bell, S.

2013 Access Granted! Barriers Endure: Determinants of Difficulties Accessing Specialist Care when Required in Ontario, Canada. BMC Health Services Research. 13(1): 146-156.

Hay, M. C.

2010 Suffering in a Productive World: Chronic Illness, Visibility and the Space Beyond Agency. American Ethnologist, 37(2): 259-274.

Hayes, R., Vaughan, C., Medeiros, T. and Dubuque, E.

2002 Stigma Directed Toward Chronic Illness Is Resistant to Change Through Education and Exposure. Psychological Reports, 90(1): 1161-1173.

Joachim, G. and Acorn, S.

2000 Stigma of Visible and Invisible Chronic Conditions. Journal of Advanced Nursing, 32(1): 243-248.

Jolly, M., Pickard, A., Mikolaitis, R., Cornejo, J., Sequeira, W., Cash, T. and Block, J.

2012 Body Image In Patients with Systemic Lupus Erythematosus. International Journal of Behavioral Medicine, 19(1): 157-164.

Kleinman, A.

1988 The Illness Narratives: Suffering, Healing \& the Human Condition. Basic Books: New York, NY.

Lupus Canada

2014 http://lupuscanada.org/index.html, accessed April 6, 2014.

Lupus Ontario

2009 http://www.lupusontario.org/, accessed March 10, 2014 
McKay, K and Smith, D.

2014 "How to Prepare for your Specialist Medical Appointments". Lecture, the Ottawa Hospital Arthritis Centre and the Arthritis Team, Ottawa, On, March 12, 2014

Miah, A. and Rich, E.

2008 The Medicalization of Cyberspace. Routledge: New York, NY.

Miles, A.

2009 Of Butterflies and Wolves: Enacting Lupus Transformations on the Internet. Anthropology \& Medicine, 16(1): 1-12.

2013 Living with Lupus: Women and Chronic Illness in Ecuador. University of Texas Press: Austin, TX.

Miserandino, C.

2003 The Spoon Theory. http://www.butyoudontlooksick.com/navigation/BYDLSTheSpoonTheory.pdf, accessed April 7, 2014.

Murphy, K. A., Spence, S. T., McIntosh, C. N. and Gorber, S. K. C.

2006 Health State Descriptions for Canadians: Musculoskeletal Diseases. Statistics Canada: Ottawa, On.

Nery, F., Borba, E., Hatch, J., Soares, J., Bonfa, E. and Neto, F.

2007 Major Depressive Disorder and Disease Activity in Systemic Lupus Erythematosus. Comprehensive Psychiatry, 48(1): 14-19.

Okada, $\mathrm{H}$.

2011 Chapter 7: Negotiating the Invisible: Two Women making sense of Chronic Illness through Narrative. In Language, Body, and Health, Paul McPherron and Vaidehi Ramanathan (eds.). Walter de Gruyter Inc.: Berlin, Germany. Pp. 145-170.

Parsons, T.

1951 The Social System. London: Routledge.

Pederson, A. and Liwander, A.

2012 Chapter 2: Primary Health Care for Women in Canada. In Thinking Women and Health Care Reform In Canada, Pat Armstrong, Barbara Clow, Karen Grant, Margaret Haworth-Brockman, Beth Jackson, Ann Pederson and Morgan Seeley (eds.). Women's Press: Toronto, On. Pp. 37-64.

Sanz, I., Yasothan, U. and Kirkpatrick, P.

2011 Belimumab. Nature Drug Discovery, 10(5): 335-336. 
Schaefer, K.

1995 Struggling to Maintain Balance: A Study of Women living with Fibromyalgia. Journal of Advanced Nursing, 21(1): 95-102.

Scofield, L., Reinlib, L., Alarcon, G. and Cooper, G.

2008 Employment and Disability Issues in Systemic Lupus Erythematosus: A Review. Arthritis \& Rheumatism (Arthritis Care \& Research). 59(10): 1475-1479

Sehlo, M. and Bahlas, S.

2013 Perceived Illness Stigma is Associated with Depression in Female Patients with Systemic Lupus Erythematosis. Journal of Psychosomatic Research, 74(1): 248251.

Sherry, M.

2004 Overlaps and Contradictions between Queer Theory and Disability Studies. Disability \& Society, 19(7): 769-783.

Shildrick, M.

1997 Leaky Bodies and Boundaries: Feminism, Postmodernism and (Bio)Ethics. Routledge: New York, NY.

Silliker, A.

2012 People with Episodic Disabilities Valuable Talent. Canadian HR Reporter, on February 12, 2012, issue 25(3), pg. 1,19.

Sutanto, B., Singh-Grewal, D., McNeil, P., O’Neill, S., Craig, J., Jones, J. and Tong, A.

2013 Experiences and Perspectives of Adults Living with Systemic Lupus Erythematosus: Thematic Synthesis of Qualitative Studies. Arthritis Care \& Research, 65(11): 17521765.

Vick, A.

2012 Theorizing Episodic Disabilities: The Case for an Embodied Politics. Canadian Social Work Review, 29(1): 41-60.

Vick, A. and Lightman, E.

2010 Barriers to Employment Among Women with Complex Episodic Disabilities. Journal of Disability Policy Studies, 21(2): 70-80.

Vickers, M.

2001a Unseen Chronic Illness and Work: Authentic Stories. Women in Management Review. 16(2): 62-74.

2001b Work and Unseen Chronic Illness: Silent Voices. Routledge: New York, NY. 
Voss Jr., E. and Casperson, G.

1988 Anti-DNA Antibodies in SLE: Historical Perspective. In Anti-DNA Antibodies in SLE eds. Edward W. Voss, Jr. (eds.). CRC Press: Boca Raton, Florida. Pp. 2-15.

Ware, N.

1992 Suffering and the Social Construction of Illness: The Delegitimation of Illness Experience in Chronic Fatigue Syndrome. Medical Anthropology Quarterly, 6(4): 347-361.

Withers, A.

2012 Disability Politics and Theory. Fernwood Publishing: Black Point, NS.

Yelin, E., Trupin, L., Katz, P., Criswell, L., Yazdany, J., Gillis, J. and Panopalis P.

2007 Work Dynamics Among Persons with Systemic Lupus Erythematosus. Arthritis \& Rheumatism (Arthritis Care \& Research). 57(1): 56-63. 